\title{
Artificial size selection experiment reveals telomere length dynamics and fitness consequences in a wild passerine
}

\author{
Michael Pepke ${ }^{1}$, Thomas Kvalnes ${ }^{2}$, Bernt Rønning ${ }^{2}$, Henrik Jensen ${ }^{2}$, Winnie Boner ${ }^{3}$, \\ Bernt-Erik Sæther ${ }^{2}$, Pat Monaghan ${ }^{3}$, and Thor Harald Ringsby ${ }^{2}$ \\ ${ }^{1}$ Norges teknisk-naturvitenskapelige universitet \\ ${ }^{2}$ Norwegian University of Science and Technology \\ ${ }^{3}$ Glasgow University
}

February 28, 2021

\begin{abstract}
Changes in telomere dynamics could underlie life-history trade-offs among growth, size and longevity, but our ability to quantify such mechanistic processes in natural, unmanipulated populations is limited. We investigated how 4 years of artificial selection for either larger or smaller body size affected early-life telomere length in two insular populations of wild house sparrows. A negative correlation between telomere length and structural size was evident under both selection regimes. The study also revealed that male sparrows had longer telomeres than females, after controlling for size, and there was a significant negative effect of harsh weather conditions on telomere length. The long-term fitness consequences of these changes in early-life telomere length induced by the artificial size selection were explored over a period of 11 years. These analyses indicated disruptive selection on telomere length because both short and long early-life telomere length tended to be associated with the lowest mortality rates and highest life expectancy. There was also weak evidence for a negative association between telomere length and annual reproductive success, but only in the population where body size was increased experimentally. Our results suggest that natural selection for optimal body size in wild animals will affect early-life telomere length during growth, which is known to be linked to longevity in birds, but also that the importance of telomeres for long-term somatic maintenance and fitness is complex in a wild bird species.
\end{abstract}

\section{INTRODUCTION}

Telomeres, the nucleoprotein complexes involving tandem repeats of a non-coding DNA sequence, prevent the ends of linear chromosomes from inappropriately activating the DNA repair machinery (Blackburn, 1991). In the absence of restoration, telomeres shorten with each cell division due to incomplete replication of DNA at the chromosome ends, and their eventual dysfunction limits cell replicative potential (Hayflick, 1965). Telomeres may be further eroded by other processes including oxidative damage (von Zglinicki, 2002; Reichert \& Stier, 2017). Telomere length (TL) changes might therefore reflect the cumulative costs associated with acquiring and maintaining a particular body size, since this is linked to cell replication levels (Monaghan \& Ozanne, 2018), as outlined in Fig. 1. The functional relationships between size, growth and telomere dynamics might thus play an important role in shaping the optimal body size in wild species under natural selection (Ringsby et al. 2015; Erten \& Kokko, 2020). Body size is a fundamental species characteristic, which is intertwined with many aspects of species ecology and evolution (Haldane, 1928; Peters, 1983; Woodward et al., 2005; Sibly \& Brown, 2007), and is under directional selection in many species (Kingsolver \& Pfennig, 2004). Both across and within species, body size has been shown to correlate with important fitness-related traits including survival, lifespan, fecundity and metabolic rate (Bumpus, 1899; Gaillard et al., 1989; White et al., 2019). Life-history theory predicts that organisms need to allocate their limited available energy among different components of fitness, which leads to trade-offs and selection 
for optimal solutions (Stearns, 1989). Trade-offs between life-history traits may also occur due to antagonistic interactions; for instance, if allocation of energy into developmental growth has negative consequences due to long-term effects of telomere shortening (Fig. 1, Monaghan et al., 2009; Young, 2018). For instance, Heidinger et al. (2012) demonstrated a negative relationship between early-life TL and lifespan in captive zebra finches (Taeniopygia guttata). Negative correlations between fitness-related traits may conform to the hypothesized life-history trade-offs (Futuyma, 2010), but they are difficult to observe in the wild, for instance due to variation among individuals in resource acquisition (van Noordwijk and de Jong 1986) and random environmental variation (Pujol et al., 2018). Nonetheless, physiological or genetic constraints generating life-history trade-offs may be detected by comparing different phenotypes or genotypes (Reznick, 1985), or through experimental manipulations involving for example natural selection in a controlled environment or artificial selection in the traditional breeder's approach (Connor, 2003; Postma et al., 2007; Pick et al., 2020). Correlated responses to artificial selection then suggest additive genetic covariance between a trait and the selected trait (Connor, 2003).

Several studies have investigated potential for telomere dynamics to underpin individual variation in lifehistory strategies (Monaghan, 2010; 2014; Selman et al., 2012; Vedder et al., 2017). In the wild, many of these studies, including long-lived bird species, mammals and reptiles, suggest that most telomere loss occur during early life (Hall et al., 2004; Spurgin et al., 2018) and that TL may be negatively correlated with various developmental stress factors at this stage (Fig. 1), including brood competition (Boonekamp et al., 2014; Nettle et al., 2016), poor nutrition and catch-up growth (Jennings et al., 1999; Geiger et al., 2012). Such factors may result in the release of stress hormones, which have been shown experimentally to increase early-life telomere loss in the wild (Herborn et al., 2014), and oxidative stress (Reichert \& Stier, 2017) that may directly increase the shortening of telomeres. In addition, body size has been shown to negatively correlate with TL within different tetrapod species (Scott et al., 2006; Pauliny et al., 2006; Debes et al., 2016; Caprioli et al., 2013; Ringsby et al., 2015; Spurgin et al., 2018), which is thought to be due to the additional number of cell divisions required for acquiring larger size, and the increased oxidative stress associated with maintaining larger size (Monaghan \& Ozanne, 2018). The emerging field of telomere ecology aims to identify factors that influence variation in individual TL and their potential fitness consequences in free-living animals (Spurgin et al., 2018). Whether there is a causal relationship between telomere dynamics and individual variation in fitness in populations in the wild and if TL is an indicator of individual quality are not yet fully understood (Simons, 2015; Angelier et al., 2019). Experimental approaches in both the field and the laboratory play an important role in increasing our understanding of TL and life-history evolution.

In a large scale experimental study conducted in the wild, an artificial directional selection regime on body size, as indicated by tarsus length, was imposed annually and in opposite directions during four consecutive years in two island populations of wild house sparrows (Passer domesticus ) in northern Norway (Fig. 2). Each winter, adult sparrows with tarsus lengths smaller or larger than given thresholds were removed from each population to produce a significant bidirectional change in mean tarsus length across the adult breeding populations (Kvalnes et al., 2017). Relatively high heritabilities for tarsus length have been found in these house sparrow populations ( $h^{2}=0.3-0.4$, Kvalnes et al., 2017), thus we expected, based on the Breeder's equation (Lande, 1979), the artificial selection to result in significant responses in offspring tarsus lengths and growth rates. Here, we initially show how the artificial selection on parental tarsus length affected the size of their offspring measured during the nestling stage. Tarsus length is commonly used as a proxy for structural body size in house sparrows (Rising \& Somers, 1989; Araya-Ajoy et al. 2019). In a previous study based on a subsample of chicks from the population undergoing artificial selection for larger body size, Ringsby et al. (2015) showed that the selection regime had indeed extended the range of chick body size at its upper end, and that this was associated with a reduction in TL in red blood cells. In this study, we examined whether the reciprocal effect, leading to longer TL, occurred in the population in which body size was reduced, and also examined the results in chicks whose parents were not subjected to the selection regime. We constructed genetic pedigrees to identify nestlings with parents that were subjected to artificial selection. We then investigated how individual TL in nestling cohorts changed under the different size selection regimes: We expected that increasing body size through artificial selection led to shorter 
TLs through increased number of cell divisions (Falconer et al., 1978) and oxidative stress associated with increased energy expenditure (Geiger et al., 2012; Pauliny et al. 2015; Smith et al., 2016; Monaghan \& Ozanne, 2018). Similarly, we expected that smaller body size and thus decreased nestling growth led to a slower rate of TL reduction (Vedder et al., 2018). Since TL was measured in early-life (fledgling stage) we also examined environmental factors previously shown to influence telomere loss during this period (Chatelain et al., 2020), specifically brood competition (Boonekamp et al., 2014) and weather conditions (Graham et al., 2019).

The artificial selection was expected to shift the populations away from their optimal body size and increase the phenotypic variance across the populations (Kvalnes et al., 2017). Here, we investigated whether changes in TL following the artificial size selection might mechanistically underpin fitness effects due to the deviation from the optimal body size. Thus, the survival and reproduction of all individuals on both islands were monitored during and after the selection events. Hypothesizing that shorter TL relative to body size would be associated with lower survival and reduced lifespan (Heidinger et al., 2012), because short telomeres reflect adverse early-life conditions (Wilbourn et al., 2018; Eastwood et al, 2019), we tested the effect of TL on short-term (first-year) survival under the two selection regimes, and on long-term survival (lifespan) after the artificial selection events. Similarly, we tested if longer early-life TL predicted higher future reproductive success (e.g. Pauliny et al., 2006; Olsson et al., 2011; Heidinger et al., 2012; Bauch et al. 2013) and if any of the potential trade-offs (Fig. 1) were affected by the artificial selection.

\section{MATERIALS AND METHODS}

\section{Study system and sampling}

The study was performed on the islands of Vega $\left(163 \mathrm{~km}^{2}, 65^{\circ} 40^{\prime} \mathrm{N}, 11^{\circ} 55^{\prime} \mathrm{E}\right)$ and Leka $\left(57 \mathrm{~km}^{2}, 65^{\circ} 06^{\prime} \mathrm{N}\right.$, $11^{\circ} 38^{\prime} \mathrm{E}$ ) off the coast of northern Norway (Fig. S1.1) in the years 2002-2012. The house sparrow is a small sedentary passerine (Anderson, 2006), thus the geographical separation of the islands (52 km) ensured no dispersal between populations (Kvalnes et al., 2017). The average generation time in similar populations is about 2 years (Jensen et al., 2008), and average lifespan is about 2 years (Jensen et al., 2004), but the maximum recorded lifespan is 13 years in the wild (Klimkiewicz \& Futcher, 1987). Both study islands are dominated by cultivated land (silage production), heathland, mountains, and sparse forest. The sparrows live closely associated with humans mainly on dairy farms on these islands, where they nest in holes and cavities and have access to food (grain) and shelter all year. During the breeding season (mid-May to midAugust) from 2002-2006 all accessible and active nests (they can lay up to 3 broods per season with on average $4.6 \pm 0.06$ eggs) were visited at least every $9^{\text {th }}$ day. Laying and hatching date were recorded for each brood (207 broods from 158 nests) and chicks were marked as fledglings (ca. 11 days old, ranging from 5-17 days) with a numbered metal ring and plastic color rings for identification. Mist-netting during the breeding season, in autumn (September-November), and in late winter (February-March) ensured that around 90\% of the winter population at both islands were marked at all times during the study (see Kvalnes et al., 2017). For all fledglings and adults, tarsometatarsus (tarsus) length was measured using calipers to the nearest $0.01 \mathrm{~mm}$. Because tarsus length increases with nestling age, we estimated standardized tarsus length as the residuals of a linear regression of tarsus length on age separately for each sex and population. Age-corrected nestling tarsus length is a good predictor of adult tarsus length (Fig. S1.2, $r=0.74$, for $n=220$ birds that were recaptured as adults). To minimize disturbance, fledglings were measured only once in the nest, thus, individual growth rates were not directly monitored. However, within species in which growth is seasonally constrained, larger individuals generally grow faster (Metcalfe \& Monaghan, 2003). A small blood sample (25 $\mu \mathrm{L}$ ) was collected from all nestlings around 11 days (5-17 days) old by puncturing the brachial vein. Blood was stored in $1 \mathrm{ml}$ absolute ethanol at room temperature in the field and subsequently in the laboratory at $-20^{\circ} \mathrm{C}$ until DNA extraction.

\section{Artificial selection on tarsus length}

In February and early March each year from 2002 to 2012 (11 years, Fig. 2) ca. 90\% of the house sparrows on Leka ( $n=89-222$ per year) and Vega $(n=102-352$ per year) were caught using mist-netting in or around 
farms and then held in separate aviaries for up to 12 days withad libitum water and food (sunflower seeds, cattle grain and bread) to obtain morphological measurements. During 2002-2005, adult sparrows with tarsi shorter (Leka, referred to as the highpopulation) or longer (Vega, referred to as the low population) than the island population mean $\pm 0.3 \mathrm{SD}$, within each sex, were translocated to distant localities (Ranke et al., 2020) and thus removed from the breeding populations (see Kvalnes et al., 2017 for details of the selection procedure). Thus, both populations were subject to the same artificial selection pressure, but in opposite directions. On average, $56.4 \%$ (highpopulation) and $62.9 \%$ (lowpopulation) of the captured individuals were removed each year, whereas the selected birds were released back at their capture location. Thus, because ca. $10 \%$ of the individuals present at the time of selection were not captured, the artificially selected individuals constituted ca. 78\% of the breeding populations (Kvalnes et al., 2017). In the first year (2002) of the selection experiment, there was no significant difference in average fledgling tarsus lengths between the highand low populations $\left(n=167, \beta_{\lambda \text { дo }}=0.22\right.$, lower and upper $95 \%$ confidence interval $(\mathrm{CI})=[-0.25,0.70]$ accounting for age at sampling and sex). In the years following the end of the selection experiment (from 2006) all birds were released back at the original capture location (Rønning et al., 2016).

\section{Weather data}

For each nestling, local weather data retrieved from The Norwegian Meteorological Institute (2018) were averaged over 30 days prior to sampling (at around 11 days old) in order to reflect average environmental conditions before and during the nestling growth phase (see Appendix S1). Due to intercorrelation among weather data variables (Fig. S1.3), we used principal component analysis (Fig. S1.4 and Table S1.1) to explore relationships between local weather variables and the regional daily North Atlantic Oscillation (NAO) index (retrieved from the National Oceanic and Atmospheric Administration, 2019) averaged over the same 30-day period (NAO_30). In Appendix S1, we show that the NAO_30 index is positively correlated with temperature, humidity and atmospheric pressure and negatively correlated with wind speed and amount of precipitation in our study area and therefore might be used as a simple index of overall harshness of weather conditions during the nestling stage; negative and positive NAO_30 indexes may indicate "harsh" and "benign" conditions, respectively (e.g. Stenseth et al., 2003).

\section{Molecular analyses}

DNA extraction of the collected blood samples is described in Appendix S1. Relative erythrocyte TLs were measured in all nestlings ( $n=566$, average age $10.9 \pm 1.5$ days) from 2002-2006 (5 cohorts from two populations, Fig. 2) using the real-time quantitative polymerase chain reaction (qPCR) amplification method as described by Cawthon et al. (2002) and with modifications by Criscuolo et al. (2009). The qPCR method measures the ratio of the telomere repeat copy number amount of telomere sequence to a control single copy gene number (a non-variable "housekeeping" gene; GAPDH) relative to a reference sample. This ratio is referred to as the relative telomere length (TL). DNA samples were diluted with $\mathrm{dH}_{2} \mathrm{O}$ to yield 1.67 $\mathrm{ng} / \mu \mathrm{L}$ (corresponding to $10 \mathrm{ng}$ of DNA per well in the PCR assay) and subsequently stored at $-78^{\circ} \mathrm{C}$. All samples were randomized and run in triplicates on 96-well plates, each plate including a 2-fold serial dilution (40-2.5 ng/well) of a "standard sample" of DNA from a single individual used to produce standard curves for each plate, a non-target control sample, and the reference sample (all in triplicates). Following Ringsby et al. (2015), PCR assays were prepared using the Absolute blue qPCR SYBR green Low Rox master mix (ThermoFisher scientific) and run using a Stratagene Mx3005p system and analyzed using the MxPro qPCR software (Agilent). Primers and thermal profiles are specified in Appendix S1. Relative TLs were calculated taking plate amplification efficiencies (all within $100 \pm 10 \%$, mean telomere assay efficiency was $102.2 \pm 3.8 \%$, and $101.9 \pm 3.4 \%$ for GAPDH assays across $2 \times 21$ plates) into account using the Pfaffl (2001) method. All telomere analyses were performed at the University of Glasgow and included 507 individuals measured by MLP (this study) and 60 individuals (a subset of both male and female nestlings from both populations from 2002 and 2005) measured by WB under identical laboratory conditions and using the same reference sample (Ringsby et al., 2015). The average of the reference sample cycle thresholds (Ct) across all plates were $9.42 \pm 0.13 \mathrm{SD}\left(\mathrm{CV}_{\text {interplate }}=1.39 \%, \mathrm{CV}_{\text {intraplate }}=0.72 \%\right)$ for telomere assays and $20.58 \pm 0.09 \mathrm{SD}$ $\left(\mathrm{CV}_{\text {interplate }}=0.46 \%, \mathrm{CV}_{\text {intraplate }}=0.40 \%\right)$ for $\mathrm{GAPDH}$ assays. 
Molecular sexing and pedigree reconstruction are described in Appendix S1. Each nestling was classified into one of three selection categories (sample sizes are shown in Table 1): Selected (1): Both parents had been subject to the selection regime, i.e. captured during a winter selection event and allowed to stay in the population. Intermediate (0.5): one parent had been subject to artificial selection. Unselected (0): No parents had been artificially selected (i.e. accidentally not captured during any winter selection event) and these individuals are therefore the unselected controls. Unknown genetic parents were assumed not to have been artificially selected (i.e. not captured or immigrated after the selection event and thus not included in the pedigree).

\section{Statistical analyses}

Temporal changes in telomere and tarsus lengths during artificial selection

In order to analyze how nestling tarsus length and TL were affected by the artificial selection for longer (high ) and shorter tarsi (low ) during the study from 2002-2006, we used linear mixed effects models (R package lme4, Bates et al. 2015) including year (i.e. birth cohort 1 to 5) as a continuous predictor variable, as well as the quadratic effect of year $\left(\right.$ year $\left.^{2}\right)$. Tarsus length and TL are expected to change during development within individual nestlings (Hall et al., 2004; Boonekamp et al., 2014) and there might be sexual differences in morphology (Cordero et al., 2000) and telomere dynamics (Barrett \& Richardson, 2011). Thus, nestling age (number of days since hatching) and sex were included as explanatory variables in all models. Selection status category $(0,0.5$, or 1$)$ was included in addition to an interaction term between selection status and year. All models assumed a Gaussian error distribution and included a random intercept for brood identity to account for the non-independence of nestlings from the same brood. We structured these analyses into four sections, where we analyzed each selection regime ( $h i g h$ or low population) separately for each response variable (tarsus length and TL). In order to identify the predictors most supported by the empirical data we constructed and compared alternative candidate models (Burnham \& Anderson, 2002) fitted with maximum likelihood within each section using Akaike's information criterion (Akaike, 1973) corrected for small sample sizes (AICc, Hurvich \& Tsai, 1989). All models were validated visually by diagnostic plots and model parameters are given from models refitted with restricted maximum likelihood (REML). To reduce the problem of multicollinearity in multiple regression analyses, we only included predictor variables with intercorrelation Pearson's $r<0.5$ for all relevant pairs of explanatory variables. All statistical analyses were performed in $\mathrm{R}$ version 3.5.2 (R Core Team, 2018).

\section{Effects of body size and weather on telomere length}

We investigated factors affecting fledgling TL (response variable) by constructing 30 biologically plausible linear mixed effects models with combinations of the explanatory variables sex, age, standardized tarsus length, brood size (number of chicks in the nest at the time of sampling), and the NAO_30 index. In addition, an interaction term between island population identity (i.e. high or lowselection regime) and tarsus length was included in some models to test for an effect of the artificial selection regimes on the relationship between TL and tarsus length. Brood identity and year (cohort) effects were accounted for by inclusion as random intercepts in all models. Again, candidate models were compared using AICc.

\section{Effects of telomere length on survival}

The effect of nestling TL on short- and long-term survival was analyzed using two different approaches: First, we analyzed the effect of TL on first-year survival (i.e. before removal of artificially selected individuals) using generalized mixed effects linear models (lme4package) with a binomial error distribution and a logit link function (logistic regression) using the bobyqa optimizer from the 'minca' package throughout to improve model convergence (Bates et al., 2014). Birds that were never observed after the season in which they were born (effectively after end of January when field work recommenced the year after they were born) were considered to be dead. Thus, mortality and emigration have the same effect on the local population. The house sparrows show strong site fidelity and generally do not display adult dispersal (Anderson, 2006; Pärn et al., 2009), such that any emigrants do not return to the natal population. We used AICc to compare 26 candidate models including TL, tarsus length, non-linear effects of TL and tarsus length (TL ${ }^{2}$ and tarsus 
length ${ }^{2}$ ), the NAO_30 index, and an interaction term between tarsus length and population identity, and between TL and population identity, respectively, as explanatory variables. Population identity and sex were included as fixed factors, and brood identity and year were included as random intercepts in all models.

Second, to test the effect of fledgling TL on survival throughout the life of individuals we used multivariate Cox proportional hazards regression to estimate hazard ratios (HR) relative to the baseline sample mean mortality within each strata of all predictor variables. HR is defined as the relative risk of death occurring at a given interval of time compared to the total population (Cox, 1972). Thus, a HR $>1$ indicates an increased mortality given an increase in the trait. 26 candidate models were constructed using thesurvival package (Therneau, 2015) including TL, tarsus length, non-linear effects of TL and tarsus length, the NAO_30 index, and interaction terms between population identity and tarsus length or TL, respectively. Sex and population identity were included as fixed factors in all models, which were then compared using AICc. Individuals that were removed during the artificial selection were right-censored and the last observation of an individual was used as an estimate of the (minimum) lifespan measured in number of days since hatching. This procedure appropriately accounts for the right-censoring caused by the artificial removal of individuals, but underestimates absolute survival probabilities, as recapture rates were not accounted for in this approach. However, since both populations were carefully monitored each year, we can assume that $>90 \%$ of the individuals that were present in the study populations were recorded from year to year (Kvalnes et al., 2017), and that the total observation interval correlates with lifespan. No other birds were censored as observations continued until 2012; two years after the last record of any sampled individual (in 2010). The proportional hazards assumption was tested using the correlation between scaled Schoenfeld residuals and time. We accounted for possible non-independence of broods by including brood identity as random factor (cluster).

\section{Effects of telomere length on reproductive success}

Finally, the effect of fledgling TL on the total number of recruits produced per individual (LRS, lifetime reproductive success) was analyzed. We included only individuals that survived until breeding and that were not removed during the artificial selection (and thus allowed to reproduce). In the high population, 10 out of 22 recruiting individuals produced at least one recruit and 39 out of 80 individuals did so in the low population. While reproduction per semay accelerate telomere loss (Sudyka, 2019), we test here the predictive value of early-life TL and/or tarsus length on subsequent reproductive output (Eastwood et al., 2019). Since LRS and lifespan (measured in years from first to last observation) were highly correlated (high population; Pearson's $r=0.83, p<0.0001$, low population; Pearson's $r=0.70, p<0.0001$ ), we tested whether TL or tarsus length predict LRS while controlling for lifespan (which is equivalent to the individual average annual reproductive success, ARS). We fitted a set of generalized linear mixed models with a Poisson error distribution separately for each population to facilitate model convergence, using the package glmmTMB (Brooks et al. 2017). Sex was included as fixed factor and brood identity and year were included as random intercepts in all models. We compared the same 9 candidate models for each population using AICc and models were validated using the DHARMa package (Hartig, 2019).

\section{RESULTS}

\section{Temporal changes in tarsus and telomere lengths during artificial selection}

In the high population, the tarsus of fledglings with both parents artificially selected was on average longer than the tarsus of fledglings produced by unselected individuals (i.e. with parents not subjected to artificial selection; model ranked 1, selected vs. unselected: $\beta_{\sigma \epsilon \lambda \epsilon \varsigma \tau \epsilon \delta}=0.52, \mathrm{CI}=[0.04,1.02]$, Fig. 3b, Tables S2.1 and S2.2), and tended to be shorter than tarsus of fledglings produced by unselected individuals in the lowpopulation (model ranked 2, [?] AICc $=0.6$, selected vs. unselected: $\beta_{\sigma \epsilon \lambda \epsilon \varsigma \tau \epsilon \delta}=-0.38, \mathrm{CI}=[-0.80,0.03]$, Fig. $4 \mathrm{~b}$, Table S2.1). Intermediate individuals with one artificially selected parent showed a similar weak tendency when compared to the unselected (high: $\beta_{\imath \nu \tau \epsilon \rho \mu \epsilon \delta i a \tau \epsilon}=0.25, \mathrm{CI}=[-0.21,0.72] ;$ low $: \beta_{\imath \nu \tau \epsilon \rho \mu \epsilon \delta i a \tau \epsilon}=-0.31$, CI=[$0.69,0.08]$, Figs. 3b and 4b, Tables S2.1 and S2.2). Across the study period (2002-2006), fledgling tarsus length increased linearly in the high population $\left(n=158\right.$, model ranked $1: \beta_{\psi \epsilon a \rho}=0.70, \mathrm{CI}=[0.01,1.38]$, Figs. 
3a, S2.1 and S2.2, Tables S2.1 and S2.2) and decreased linearly in the lowpopulation ( $n=408$, model ranked 1: $\beta_{\psi \epsilon a \rho}=-0.63, \mathrm{CI}=[-1.23,-0.04]$, Figs. 4a, S2.1 and S2.2, Tables S2.1 and S2.2). In both populations, there was weak evidence (i.e. marginally significant) for a curvilinear change over the years, indicating that after the initial divergence the change in tarsus length ceased (high, model ranked 1: $\beta_{\psi \epsilon a \rho^{\wedge} 2}=-0.09, \mathrm{CI}=[-0.20$, 0.03]; low , model ranked 1: $\beta_{\psi \in a \rho^{\wedge} 2}=0.10, \mathrm{CI}=[-0.00,0.20]$, Figs. 3a and 4a, Table S2.2).

TL of fledglings with both parents artificially selected was not different from those of unselected individuals in the highpopulation (model ranked 3, [?]AICc $=0.7$, selected vs. unselected: $\beta_{\sigma \in \lambda \epsilon \varsigma \tau \epsilon \delta}=0.02, \mathrm{CI}=[-0.18$, 0.22], Fig. 3d, Tables S2.1) nor in the low population (model ranked 3, [?]AICc=3.0, selected vs. unselected: $\beta_{\sigma \in \lambda \epsilon \varsigma \tau \epsilon \delta}=0.03, \mathrm{CI}=[-0.07,0.13]$, Fig. 4d, Table S2.1). However, intermediate individuals with one artificially selected parent showed weak evidence for a tendency towards shorter telomeres when compared to the unselected in the high population $\left(\beta_{\imath \nu \tau \epsilon \rho \mu \epsilon \delta i \tau \epsilon \epsilon}=-0.13, \mathrm{CI}=[-0.32,0.07]\right.$, Fig. 3d), and towards longer telomeres compared to unselected individuals in the low population $\left(\beta_{\imath \nu \tau \epsilon \rho \mu \epsilon \delta i q \tau \epsilon}=0.05, \mathrm{CI}=[-0.05,0.15]\right.$, Fig. 4d). Across the study period, fledgling TL decreased linearly in the high population (model ranked 2, [?] AICc $=0.0: \beta_{\psi \epsilon a \rho}=-0.26, \mathrm{CI}=[-0.50,-0.01]$, Figs. 3c and S2.1, Tables S2.1 and S2.2), but there was no change in thelow population (model ranked 2, [?] $\mathrm{AICc}=1.9: \beta_{\psi \epsilon a \rho}=0.01, \mathrm{CI}=[-0.02,0.03]$, Figs. $4 \mathrm{c}$ and S2.1, Table S2.1). In the high population there was weak evidence for a curvilinear change over the years, indicating that after the initial increase the change in TL ceased (model ranked 2: $\beta_{\psi \epsilon a \rho^{\wedge} 2}=0.04, \mathrm{CI}=[-0.00$, 0.08], Fig. 3c, Table S2.2), but there was no evidence for any curvilinear change in thelow population (model ranked 4, [?] $\mathrm{AICc}=0.7: \beta_{\psi \epsilon a \rho^{\wedge} 2}=0.01, \mathrm{CI}=[-0.01,0.03]$, Fig. 4c). The model ranked 1 in the low population included only sex and age (Table S2.1 and S2.2). Overall, our results show some evidence for an inverse association between changes in tarsus length and TL across cohorts in populations where body size is shifted away from its optimum.

\section{Effects of body size and weather on telomere length}

Combining data from both populations $(n=566)$, TL was found to be negatively related to tarsus length

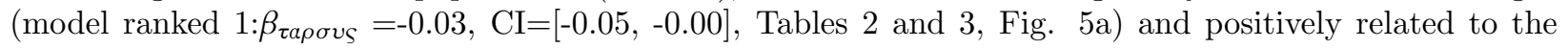
NAO_30 index $\left(\beta_{N_{A O} 30}=0.10, \mathrm{CI}=[0.01,0.19]\right.$, Fig. $\left.5 \mathrm{~b}\right)$. This means that telomeres are shorter in larger individuals and when overall weather conditions are harsh (Appendix S1). In addition, TLs were shorter in females than males $\left(\beta_{\varphi \epsilon \mu a \lambda \epsilon}=-0.08, \mathrm{CI}=[-0.14,-0.02]\right)$, and TLs were shorter in the low population compared to the highpopulation $\left(\beta_{\lambda o \omega}=-0.17, \mathrm{CI}=[-0.24,-0.10]\right)$. The second-best model ([?]AICc=0.2) showed weak evidence that the negative relationship between TL and tarsus length tended to be steeper in

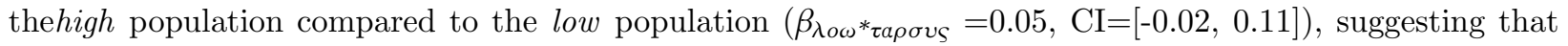
artificial selection for longer tarsus had a stronger effect on TL compared to selecting for shorter tarsus. There was little evidence for any effect of nestling age on TL (model ranked 3, [?]AICc=1.4, $\beta_{a \gamma \epsilon}=0.01$, $\mathrm{CI}=[-0.01,0.03]$, Table 2).

\section{Effects of telomere length on survival}

Average first-year survival from fledging to recruitment was $29 \%$ and maximum recorded lifespan was 5.7 years with a mean of $152 \pm 11$ days $(n=566)$. There was a positive effect of tarsus length on first-year survival (i.e. recruitment probability) that was present in four out of five models with [?]AICc $<2$ (model ranked 1: odds ratio $(O R)_{\text {tarsus }}=1.27, \mathrm{CI}=[1.04,1.57]$, Table 4$)$. In addition, there was weak evidence for a curvilinear effect of tarsus length on first-year survival present in the best model $\left(O R_{\text {tarsus }^{\wedge} 2}=1.08, \mathrm{CI}=[0.99,1.67]\right)$, indicating higher recruitment probability for individuals both smaller and larger than the average. The third-best model ([?]AICc=1.5) suggested that the positive effect of tarsus length on first-year survival was stronger in the high population compared to thelow population $\left(O R_{\text {low }} *_{\text {tarsus }}=0.71, \mathrm{CI}=[0.41,1.18]\right)$, but the effect was uncertain. In addition, there was an uncertain negative effect of TL present in one model (model ranked 5, [?]AICc $=1.9, O R_{T L}=0.89, \mathrm{CI}=[0.51,1.53]$, Table 4).

The Cox proportional hazards regression analyses of long-term survival revealed a negative effect of tarsus length on the risk of death (hazard ratio $(H R)_{\text {tarsus }}=0.91, \mathrm{CI}=[0.84,0.99]$, Tables S2.3 and S2.4, Fig. 6a). In addition, two out of four models with [?]AICc $<2$ showed weak evidence for a curvilinear effect of TL on 
mortality $\left(H R_{T L^{\wedge} 2}=0.73, \mathrm{CI}=[0.51,1.04]\right)$, indicating a bimodal pattern, where fledglings with both short and long TL have lower long-term mortality rates (Fig. 6b, Table S2.4). The curvilinear effect of tarsus length present in two out of four models with [?]AICc $<2$, was uncertain and weak, i.e. close to $1\left(H R_{\text {tarsus }^{\wedge} 2}\right.$ $=0.98, \mathrm{CI}=[0.95,1.01])$.

\section{Effects of telomere length on reproductive success}

In the high population, there was weak evidence for a negative effect of TL on LRS while controlling for lifespan (model ranked 2, [?] $\mathrm{AICc}=0.1, \beta_{T \Lambda}=-1.24, \mathrm{CI}=[-2.52,0.04]$, Tables 5 and S2.5) suggesting that individuals with short telomeres in early-life produced more recruits annually. In the lowpopulation, the best model was the simplest model including only the effects of sex and lifespan (Tables 5 and S2.5).

\section{DISCUSSION}

Much of the theoretical and empirical research on the mechanisms that shape variation in body size is based on life-history theory which suggests that individuals allocate their acquired resources between growth, reproduction, and self-maintenance (Stearns, 1989; Zera \& Harshman, 2001; Roff \& Fairbairn, 2007). In this experimental study we examined the consequences of artificial selection for larger and smaller parental body size and how this influences variation in offspring TL at early age, as well as the associations between TL and recruitment, longevity and reproductive success in two wild house sparrow populations. First, a negative correlation between nestling TL and tarsus length was evident under the artificial selection for both larger and smaller tarsi (Table 3). This link between TL and structural body size suggests that telomere dynamics might mediate a trade-off between investment in early-life growth and long-term somatic maintenance in the wild (Metcalfe \& Monaghan 2003; Ringsby et al., 2015; Monaghan \& Ozanne, 2018). Artificial selection for larger individuals in thehigh population caused TL to decrease significantly as tarsus length increased during the four years of selection (Fig. 3). Additionally, there was weak evidence that TL tended to increase as tarsus length decreased in the low population (Fig. 4). It is possible that the artificial selection for smaller body size in adults only caused a small change in offspring size because the proportion of additive genetic variance may be lower for small compared to large individuals (Charmantier et al., 2004). Thus, selecting for smaller body size for multiple years, as in our experiment, may accumulate individuals that are smaller than their predicted size due to for instance malnutrition or disease caused by e.g. environmental or parental effects (Angelier et al., 2015).

TL has been suggested as a biomarker monitoring health and stress exposure of organisms (Monaghan, 2014; Pepper et al., 2018; Chatelain et al., 2020), individual phenotypic quality (Bauch et al., 2013; Boonekamp et al., 2013; Le Vaillant et al., 2015), and as an integrated physiological marker of cumulative life-history costs (Monaghan \& Haussmann, 2006). The prevailing negative correlation between TL and body size documented in this study, indicates that TL is influenced by structural growth in free-living birds, which confirms the observation by Ringsby et al. (2015). The artificial selection pressure on body size was accompanied by a reduction in TL that was probably not counteracted within the nestling period by increased investment into telomere maintenance (i.e. canalization). Early-life changes in TL have been hypothesized to influence long-term somatic state (Eisenberg, 2011; Boonekamp et al., 2013; Vedder et al., 2017; Criscuolo et al., 2018a). The enzyme telomerase can elongate telomeres (Blackburn, 1991), but its activity is assumed to be a physiologically costly process (Hatakeyama et al., 2016; Criscuolo et al., 2018b) or with potential increased cancer risk effects (Seluanov et al., 2018). Accordingly, somatic telomerase activity is generally assumed to be repressed in birds (Gomes et al., 2010), though more investigation of this is needed since some somatic telomerase activity has been detected (Haussmann et al., 2007). In common with other non-mammalian vertebrates, birds have nucleated erythrocytes; thus, TLs derived from whole blood samples are mainly measured in erythrocytes, which are normally produced in the bone marrow. Compared to other tetrapods, avian erythrocytes have a relatively short lifespan of 1 month with $\sim 3 \%$ being replaced each day (Glomski \& Pica, 2016). Early-life erythrocyte TLs in house sparrows have been estimated to 15-20 kbp (Ringsby et al., 2015), which is thought to reflect TLs in hematopoietic stem cells (Vaziri et al., 1994). If 50-100 bp of telomeric DNA are lost with each cell division (Lansdorp, 1995), these early cells would have the potential of 150-400 divisions, many more than is needed for growth and maturation of the adult house sparrow (Sidorov 
et al., 2009). However, increased oxidative stress associated with acquiring and maintaining a larger body size (Alonso-Alvarez et al., 2007) could accelerate the shortening of telomeres significantly (Reichert \& Stier, 2017) providing an explanation for the observed negative association between size and TL (see Fig. 1 and Fig. 5a).

The evolutionary significance of the observed changes in TL induced by the artificial size selection will depend on the heritability of TL, which has been shown to vary considerably among species and populations: Among bird species, TL heritability have been shown to range from 0 to 1 (reviewed in Dugdale \& Richardson, 2018), but may be relatively low in house sparrows given the effects of growth and weather observed in this study. We have refrained from estimating heritabilities of TL in the present study, which would be biased by the non-random removal of individuals during the artificial selection events (Steinsland et al., 2014), but future studies may show whether the relationship between size and TL is underpinned by genetic correlations (Monaghan \& Ozanne, 2018).

Like most altricial passerines, the growth and survival of house sparrow nestlings depend on early-life conditions such as habitat quality and insect food being supplied by the parents (Anderson, 2006). Larger sparrows have higher juvenile and adult survival (Ringsby et al., 1998; Jensen et al., 2008), and harsh weather during the nestling period increases juvenile mortality (Ringsby et al., 2002). The associations between TL and both body size and the weather proxy (NAO_30) in nestlings (Table 3) suggest that TL is determined by complex and potentially counter-acting effects of growth, nutrition and external factors (Angelier et al., 2015; Nettle et al., 2016). For instance, malnutrition may lead to arrested growth, but also increased oxidative stress and telomere attrition (Nettle et al., 2017). Also, indirect effects of weather conditions may cause foraging stress or maternal stress effects during breeding that negatively affect TL (Haussmann et al., 2012; Mizutani et al. 2013), and direct effects of weather may cause shortening of telomeres, such as thermal stress observed in e.g. brown trout, Salmo trutta (Debes et al., 2016), dark-eyed juncos, Junco hyemalis (Graham et al., 2019) and greater-eared bats, Myotis myotis (Foley et al., 2020). Thus, generally habitat quality is important, with shorter telomeres in low-quality habitats (Angelier et al., 2013; Watson et al., 2015; Wilbourn et al., 2017). Spurgin et al. (2018) found a positive effect of seasonal insect prey abundance on TL in Seychelles warblers (Acrocephalus sechellensis ) when accounting for a negative correlation with tarsus length. In the same population, the amount of reactive oxygen metabolites in the territorial adult warblers, was shown to be higher in low quality territories than in territories of higher quality (van de Crommenacker et al., 2011), indicating that oxidative stress exposure is involved in telomere shortening (von Zglinicki, 2002). The regional NAO_30 index must be interpreted with respect to local conditions along the northern Norwegian coast but might be a better single proxy for the overall weather conditions by reducing complexity and avoiding problems of model variable selection (Stenseth et al. 2003; Hallett et al. 2004). Thus, a low NAO_30 index, which in our study area corresponds to a combination of low temperatures, strong winds and rainfall during a 30-day interval before TL sampling, was found to significantly reduce TL in nestlings, when correcting for body size (Fig. 5b). This is consistent with studies reporting shorter telomeres because of poor nutrition, competition, or thermoregulation (reviewed in Chatelain et al., 2020).

Natural selection against shorter telomeres may be driven by their negative effect on immune function and longevity (Wilbourn et al. 2018) or reduced cell replicative potential (Blackburn, 1991), while selection against longer telomeres is thought to be due to the high energetic costs associated with increased somatic maintenance (Eisenberg, 2011; Vedder et al., 2017) or increased cancer susceptibility (Aviv et al., 2017; Pepke \& Eisenberg, 2020). Several ecological and epidemiological studies have reported a negative association between TL and subsequent mortality risk; mainly in birds (reviewed in Wilbourn et al., 2018) and humans (reviewed in Boonekamp et al. 2013; Wang et al., 2018). This association can be attributed to either the biomarker characteristic of TL reflecting cumulative environmental stressors (Monaghan, 2014; Nettle et al., 2017; Pepper et al., 2018; Angelier et al., 2018) or the direct effect of having short telomeres leading to cellular senescence and certain diseases (Blackburn et al., 2015; Young, 2018). However, this correlation is not universal across tetrapods, with some studies finding no correlation in birds (Boonekamp et al., 2014), mammals (Fairlie et al., 2016), and reptiles (Olsson et al. 2011), or that shorter telomeres correlate with higher survival in birds (Wood \& Young, 2019), snakes (Ujvari \& Madsen, 2009), and fish (McLennan et al., 
2017). Ringsby et al. (2015) suggested that the changes in TL induced by the artificial size selection could underpin a trade-off between body size and lifespan if TL is related to lifespan (Heidinger et al., 2012). In this study, we found little support for an effect of TL on short-term survival (i.e. survival of juveniles until recruitment) after accounting for the positive association between tarsus length and survival (Table 4). Body size is likely to be an important component of juvenile mortality if the mortality is mainly due to extrinsic factors (Wood \& Young, 2019; Eastwood et al., 2020), as expected in juvenile house sparrows (Ringsby et al., 1998). The artificial selection increased the range of body sizes across the populations, which may more clearly reveal effects of TL on fitness. The evidence for individuals with either short or long telomeres to have reduced mortality risk through life, controlling for the negative effect of tarsus length, was weak (Fig. 6b). While some correlative studies may have overlooked such weak disruptive selection on TL, such patterns can be confounded by (unmeasured) telomerase expression in somatic cells with high proliferation rates (Klapper et al., 1998; Ujvari \& Madsen, 2009; Cerchiara et al., 2017). However, if TL is inversely related to telomere loss later in life (Verhulst et al., 2013; Bauch et al., 2014), measuring TL at a later age may generate the expected positive correlation between survival probability and TL (Wood \& Young, 2019). Alternatively, in individuals with short telomeres, TL may be traded off against some unmeasured component of individual quality (Wilson \& Nussey, 2010). Yet, when controlling for lifespan, short telomeres were associated with higher recruit production in thehigh population (Table 5). Telomere shortening rates in house sparrows are unknown, but we found little evidence for directional changes in TL across 5-17 days old nestlings (Table 2). The observation in humans that short telomeres are associated with age-dependent degenerative diseases and long telomeres with higher cancer incidence rates (Aviv et al., 2017), suggests the opposite of our findings (i.e. that both short and long TL is associated with higher mortality). However, there is probably little or no constraints on TL imposed by cancer or age-dependent diseases in free-living, short-lived sparrows (Møller et al., 2017). Combined, the adaptive significance of telomere length dynamics may be complex in wild populations with high juvenile mortality and no individuals surviving into very old age (the oldest house sparrow in this study survived until its $6^{\text {th }}$ year).

There was a weak negative effect of TL on reproductive success within individuals that survived until breeding in the population in which selection for larger size was imposed (high population, Table 5). This might suggest that there are additional negative impacts on TL associated with acquiring an artificially increased body size that deviates from the optimal body size under the prevailing conditions. Such impacts may act through increased competition when siblings are larger (Nettle et al., 2016) and increased oxidative stress during growth (Geiger et al., 2012). This indicates that in the highpopulation, high fitness birds were bigger and therefore had shorter telomeres.

Telomeres were longer in male than in female house sparrows, also when correcting for size (Table 3). We also note that males tended to have higher LRS (Table 5), but only in the high population, where just 6 males managed to reproduce at least one recruit. There were no sex-differences in survival in our study (Table S2.4), which has been suggested to underlie sex-specific telomere dynamics in humans, mice, and sand lizards (reviewed in Barrett \& Richardson 2011). In similar Norwegian house sparrow populations, Holand et al. (2016) did not find any general sex-biased mortality or senescence patterns among adults. However, Cleasby et al. (2010) found females to have lower juvenile mortality than males in an English house sparrow population. In birds and mammals, adult mortality appears to be biased towards the heterogametic sex (Liker \& Székely, 2005), which may be caused by the potentially unmasked expression of deleterious sexlinked alleles (Trivers, 1985; Hrdličková et al., 2012). In birds, females are the heterogametic sex, but sexual differences in telomere dynamics have only rarely been observed among bird species (but see Foote et al. 2011; Bauch et al., 2020). However, unmeasured sex-specific differences in growth dynamics (in house sparrows, Cleasby et al., 2011) or differential telomere loss under parasite infection (in blue tits, Cyanistes caeruleus , Sudyka et al., 2019) could also generate the observed TL sex differences.

Our study demonstrates the differential impacts of artificial body size selection on early-life TL during the important growth phase. TL was influenced by growth and weather and varied between sexes and populations. Body size was an important determinant of survival, but both short and long telomeres tended to predict lower mortality across the populations after the range of body sizes had been artificially increased. 
In individuals larger than their optimal size in the wild, TL was reduced, which may have been associated with an increased reproductive output. When selecting for smaller adult body size, we observed a smaller response in fledgling size and TL, and no relationship between TL and reproductive success. Thus, this study shows that the relationship between body size and fitness is complex, with larger body size giving rise to shorter TL. The fitness consequences of this interaction are not simple, and our experimental results suggest that evolution will optimize TL alongside phenotypic parameters.

\section{ACKNOWLEDGEMENT}

We thank all fieldworkers who collected data for this study, the island inhabitants, laboratory technician Randi Røsbak (NTNU, Trondheim) for extracting DNA and genotyping procedures, and Håkon Holand for help with parentage analyses. This work was funded by the Research Council of Norway (Centre for Biodiversity Dynamics 223257 and 274930). MLP also thanks "Forsknings- og undervisningsfondet $i$ Trondheim" for financial support. The study design was subject to review by the Norwegian Environment Agency (permits 2001/6427-ARTS/VI/ARE and 2004/1671-ARTS-VI-ID) and complied with the laws of animal welfare in Norway (permits S-2603-01, S-204-8032-1, and S-2007/1482 from the Norwegian Animal Research Authority and the Bird Ringing Centre at Museum Stavanger, Norway). The authors have no conflicts of interest to declare.

\section{REFERENCES}

Akaike, H. (1973). Information theory and an extension of the maximum likelihood principle. Paper presented at the Second International Symposium on Information Theory, Akademiai Kiado, Budapest.

Alonso-Alvarez, C., Bertrand, S., Faivre, B., \& Sorci, G. (2007). Increased susceptibility to oxidative damage as a cost of accelerated somatic growth in zebra finches. Functional Ecology, 21 (5), 873-879. doi:10.1111/j.1365-2435.2007.01300.x

Anderson, T. R. (2006). Biology of the ubiquitous house sparrow: from genes to populations . Oxford; New York: Oxford University Press.

Angelier, F., Costantini, D., Blevin, P., \& Chastel, O. (2018). Do glucocorticoids mediate the link between environmental conditions and telomere dynamics in wild vertebrates? A review. Gen Comp Endocrinol, 256 , 99-111. doi:10.1016/j.ygcen.2017.07.007

Angelier, F., Vleck, C. M., Holberton, R. L., \& Marra, P. P. (2015). Bill size correlates with telomere length in male American Redstarts. Journal of Ornithology, 156 (2), 525-531. doi:10.1007/s10336-015-1158-9

Angelier, F., Vleck, C. M., Holberton, R. L., Marra, P. P., \& Blount, J. (2013). Telomere length, non-breeding habitat and return rate in maleAmerican redstarts. Functional Ecology, 27 (2), 342-350. doi:10.1111/13652435.12041

Angelier, F., Weimerskirch, H., Barbraud, C., Chastel, O., \& Hopkins, W. (2019). Is telomere length a molecular marker of individual quality? Insights from a long-lived bird. Functional Ecology, 33 (6), 10761087. doi:10.1111/1365-2435.13307

Araya-Ajoy, Y. G., Ranke, P. S., Kvalnes, T., Ronning, B., Holand, H., Myhre, A. M., . . . Wright, J. (2019). Characterizing morphological (co)variation using structural equation models: Body size, allometric relationships and evolvability in a house sparrow metapopulation.Evolution, 73 (3), 452-466. doi:10.1111/evo.13668

Aviv, A., Anderson, J. J., \& Shay, J. W. (2017). Mutations, cancer and the telomere length paradox. Trends Cancer, 3 (4), 253-258. doi:10.1016/j.trecan.2017.02.005

Barrett, E. L., \& Richardson, D. S. (2011). Sex differences in telomeres and lifespan. Aging Cell, 10 (6), 913-921. doi:10.1111/j.1474-9726.2011.00741.x

Bates, D., Mullen, K. M., Nash, J. C., \& Varadhan, R. (2014). minqa: Derivative-free optimization 
algorithms by quadratic approximation. $\mathrm{R}$ package version 1.2.4. Retrieved from https:/CRAN.Rproject.org $/$ package $=$ minqa

Bates, D., Machler, M., Bolker, B., \& Walker, S. (2015). Fitting linear mixed-effects models using lme4. Journal of Statistical Software, 67 (1), 1-48. doi:10.18637/jss.v067.i01

Bauch, C., Becker, P. H., \& Verhulst, S. (2013). Telomere length reflects phenotypic quality and costs of reproduction in a long-lived seabird. Proc Biol Sci, 280 (1752), 20122540. doi:10.1098/rspb.2012.2540

Bauch, C., Becker, P. H., \& Verhulst, S. (2014). Within the genome, long telomeres are more informative than short telomeres with respect to fitness components in a long-lived seabird. Mol Ecol, 23 (2), 300-310. doi:10.1111/mec.12602

Bauch, C., Gatt, M. C., Granadeiro, J. P., Verhulst, S., \& Catry, P. (2020). Sex-specific telomere length and dynamics in relation to age and reproductive success in Cory's shearwaters. Mol Ecol, 29 (7), 1344-1357. doi:10.1111/mec.15399

Blackburn, E. H. (1991). Structure and function of telomeres.Nature, 350 (6319), 569-573. doi:10.1038/350569a0

Blackburn, E. H., Epel, E. S., \& Lin, J. (2015). Human telomere biology: A contributory and interactive factor in aging, disease risks, and protection. Science, 350 (6265), 1193-1198. doi:10.1126/science.aab3389

Blanckenhorn, W. U. (2000). The evolution of body size: What keeps organisms small? The Quarterly Review of Biology, 75 (4), 385-407. doi:10.1086/393620

Boonekamp, J. J., Mulder, G. A., Salomons, H. M., Dijkstra, C., \& Verhulst, S. (2014). Nestling telomere shortening, but not telomere length, reflects developmental stress and predicts survival in wild birds. Proc Biol Sci, 281 (1785), 20133287. doi:10.1098/rspb.2013.3287

Boonekamp, J. J., Simons, M. J., Hemerik, L., \& Verhulst, S. (2013). Telomere length behaves as biomarker of somatic redundancy rather than biological age. Aging Cell, 12 (2), 330-332. doi:10.1111/acel.12050

Brooks, M. E., Kristensen, K., Benthem, K. J. v., Magnusson, A., Berg, C. W., Nielsen, A., . . . Bolker, B. M. (2017). glmmTMB balances speed and flexibility among packages for zero-inflated generalized linear mixed modeling. The $R$ Journal, 9 (2), 378-400. doi:10.32614/rj-2017-066

Bumpus, H. C., \& Eugenics, G. L. f. N. (1899). The elimination of the unfit as illustrated by the introduced sparrow, passer domesticus: (a fourth contribution to the study of variation) : Gin.

Burnham, K. P., \& Anderson, D. R. (2002). Model selection and multimodel inference. A practical information-theoretic approach (2 ed.). New York, U.S.A.: Springer-Verlag.

Caprioli, M., Romano, M., Romano, A., Rubolini, D., Motta, R., Folini, M., \& Saino, N. (2013). Nestling telomere length does not predict longevity, but covaries with adult body size in wild barn swallows. Biol Lett, 9 (5), 20130340. doi:10.1098/rsbl.2013.0340

Cawthon, R. M. (2002). Telomere measurement by quantitative PCR.Nucleic Acids Research, 30 (10), e47. doi:10.1093/nar/30.10.e47

Cerchiara, J. A., Risques, R. A., Prunkard, D., Smith, J. R., Kane, O. J., \& Boersma, P. D. (2017). Telomeres shorten and then lengthen before fledging in Magellanic penguins (Spheniscus magellanicus).Aging (Albany NY), 9 (2), 487-493. doi:10.18632/aging.101172

Charmantier, A., Kruuk, L. E., Blondel, J., \& Lambrechts, M. M. (2004). Testing for microevolution in body size in three blue tit populations.J Evol Biol, 17 (4), 732-743. doi:10.1111/j.1420-9101.2004.00734.x

Chatelain, M., Drobniak, S. M., \& Szulkin, M. (2020). The association between stressors and telomeres in non-human vertebrates: a meta-analysis. Ecol Lett, 23 (2), 381-398. doi:10.1111/ele.13426 
Cleasby, I. R., Burke, T., Schroeder, J., \& Nakagawa, S. (2011). Food supplements increase adult tarsus length, but not growth rate, in an island population of house sparrows (Passer domesticus ).BMC Res Notes, 4 , 431. doi:10.1186/1756-0500-4-431

Cleasby, I. R., Nakagawa, S., Gillespie, D. O. S., \& Burke, T. (2010). The influence of sex and body size on nestling survival and recruitment in the house sparrow. Biological Journal of the Linnean Society, 101 (3), 680-688. doi:10.1111/j.1095-8312.2010.01515.x

Conner, J. K. (2003). Artificial selection: A powerful tool for ecologists. Ecology, 84 (7), 1650-1660. doi:10.1890/0012-9658(2003)084[1650:Asaptf]2.0.Co;2

Cordero, P. J., Griffith, S. C., Aparicio, J. M., \& Parkin, D. T. (2000). Sexual dimorphism in house sparrow eggs. Behavioral Ecology and Sociobiology, 48 (5), 353-357. doi:10.1007/s002650000252

Cox, D. R. (1972). Regression models and life-tables. Journal of the Royal Statistical Society. Series B (Methodological), 34 (2), 187-220. Retrieved from www.jstor.org/stable/2985181

Criscuolo, F., Bize, P., Nasir, L., Metcalfe, N. B., Foote, C. G., Griffiths, K., . . . Monaghan, P. (2009). Real-time quantitative PCR assay for measurement of avian telomeres. Journal of Avian Biology, 40 (3), 342-347. doi:10.1111/j.1600-048X.2008.04623.x

Criscuolo, F., Smith, S., Zahn, S., Heidinger, B. J., \& Haussmann, M. F. (2018). Experimental manipulation of telomere length: does it reveal a corner-stone role for telomerase in the natural variability of individual fitness? Philos Trans R Soc Lond B Biol Sci, 373 (1741), 20160440. doi:10.1098/rstb.2016.0440

Criscuolo, F., Sorci, G., Behaim-Delarbre, M., Zahn, S., Faivre, B., \& Bertile, F. (2018). Age-related response to an acute innate immune challenge in mice: proteomics reveals a telomere maintenance-related cost. Proc Biol Sci, 285 (1892), 20181877. doi:10.1098/rspb.2018.1877

Debes, P. V., Visse, M., Panda, B., Ilmonen, P., \& Vasemagi, A. (2016). Is telomere length a molecular marker of past thermal stress in wild fish? Mol Ecol, 25 (21), 5412-5424. doi:10.1111/mec.13856

Dugdale, H. L., \& Richardson, D. S. (2018). Heritability of telomere variation: it is all about the environment! Philos Trans R Soc Lond B Biol Sci, 373 (1741), 20160450. doi:10.1098/rstb.2016.0450

Eastwood, J. R., Hall, M. L., Teunissen, N., Kingma, S. A., Hidalgo Aranzamendi, N., Fan, M., . . . Peters, A. (2019). Early-life telomere length predicts lifespan and lifetime reproductive success in a wild bird. Mol Ecol, 28 (5), 1127-1137. doi:10.1111/mec.15002

Eisenberg, D. T. (2011). An evolutionary review of human telomere biology: the thrifty telomere hypothesis and notes on potential adaptive paternal effects. Am J Hum Biol, 23 (2), 149-167. doi:10.1002/ajhb.21127

Erten, E. Y., \& Kokko, H. (2020). From zygote to a multicellular soma: Body size affects optimal growth strategies under cancer risk.Evolutionary applications, 13 (7), 1593-1604. doi:10.1111/eva.12969

Fairlie, J., Holland, R., Pilkington, J. G., Pemberton, J. M., Harrington, L., \& Nussey, D. H. (2016). Lifelong leukocyte telomere dynamics and survival in a free-living mammal. Aging Cell, 15 (1), 140-148. doi:10.1111/acel.12417

Falconer, D. S., Gauld, I. K., \& Roberts, R. C. (1978). Cell numbers and cell sizes in organs of mice selected for large and small body size.Genet Res, 31 (3), 287-301. doi:10.1017/s0016672300018061

Foley, N. M., Petit, E. J., Brazier, T., Finarelli, J. A., Hughes, G. M., Touzalin, F., . . . Teeling, E. C. (2020). Drivers of longitudinal telomere dynamics in a long-lived bat species, Myotis myotis .Mol Ecol, 29 (16), 2963-2977. doi:10.1111/mec.15395

Foote, C. G., Daunt, F., Gonzalez-Solis, J., Nasir, L., Phillips, R. A., \& Monaghan, P. (2011). Individual state and survival prospects: age, sex, and telomere length in a long-lived seabird. Behavioral Ecology, 22 (1), 156-161. doi:10.1093/beheco/arq178 
Futuyma, D. J. (2010). Evolutionary constraint and ecological consequences. Evolution, 64 (7), 1865-1884. doi:10.1111/j.1558-5646.2010.00960.x

Gaillard, J. M., Pontier, D., Allaine, D., Lebreton, J. D., Trouvilliez, J., Clobert, J., \& Allaine, D. (1989). An analysis of demographic tactics in birds and mammals. Oikos, 56 (1), 59-76. doi:10.2307/3566088

Geiger, S., Le Vaillant, M., Lebard, T., Reichert, S., Stier, A., Y, L. E. M., \& Criscuolo, F. (2012). Catchingup but telomere loss: half-opening the black box of growth and ageing trade-off in wild king penguin chicks. Mol Ecol, 21 (6), 1500-1510. doi:10.1111/j.1365-294X.2011.05331.x

Glomski, C. A., \& Pica, A. (2016). The avian erythrocyte: Its phylogenetic odyssey : CRC Press.

Gomes, N. M., Shay, J. W., \& Wright, W. E. (2010). Telomere biology in Metazoa. Febs Letters, 584 (17), 3741-3751. doi:10.1016/j.febslet.2010.07.031

Graham, J. L., Bauer, C. M., Heidinger, B. J., Ketterson, E. D., \& Greives, T. J. (2019). Early-breeding females experience greater telomere loss. Mol Ecol, 28 (1), 114-126. doi:10.1111/mec.14952

Haldane, J. B. S. (1928). On being the right size. Possible worlds . London: Chatto and Windus.

Hall, M. E., Nasir, L., Daunt, F., Gault, E. A., Croxall, J. P., Wanless, S., \& Monaghan, P. (2004). Telomere loss in relation to age and early environment in long-lived birds. Proc Biol Sci, 271 (1548), 1571-1576. doi:10.1098/rspb.2004.2768

Hallett, T. B., Coulson, T., Pilkington, J. G., Clutton-Brock, T. H., Pemberton, J. M., \& Grenfell, B. T. (2004). Why large-scale climate indices seem to predict ecological processes better than local weather.Nature, 430 (6995), 71-75. doi:10.1038/nature02708

Hatakeyama, H., Yamazaki, H., Nakamura, K., Izumiyama-Shimomura, N., Aida, J., Suzuki, H., . . - Ishikawa, N. (2016). Telomere attrition and restoration in the normal teleost Oryzias latipes are linked to growth rate and telomerase activity at each life stage. Aging (Albany NY), 8 (1), 62-76. doi:10.18632/aging.100873

Haussmann, M. F., Longenecker, A. S., Marchetto, N. M., Juliano, S. A., \& Bowden, R. M. (2012). Embryonic exposure to corticosterone modifies the juvenile stress response, oxidative stress and telomere length.Proc Biol Sci, 279 (1732), 1447-1456. doi:10.1098/rspb.2011.1913

Haussmann, M. F., Winkler, D. W., Huntington, C. E., Nisbet, I. C., \& Vleck, C. M. (2007). Telomerase activity is maintained throughout the lifespan of long-lived birds. Experimental gerontology, 42 (7), 610-618. doi:10.1016/j.exger.2007.03.004

Heidinger, B. J., Blount, J. D., Boner, W., Griffiths, K., Metcalfe, N. B., \& Monaghan, P. (2012). Telomere length in early life predicts lifespan. Proc Natl Acad Sci U S A, 109 (5), 1743-1748. doi:10.1073/pnas.1113306109

Holand, H., Kvalnes, T., Gamelon, M., Tufto, J., Jensen, H., Parn, H., . . . Saether, B. E. (2016). Spatial variation in senescence rates in a bird metapopulation. Oecologia, 181 (3), 865-871. doi:10.1007/s00442016-3615-4

Hrdličková, R., Nehyba, J., Lim, S. L., Grützner, F., \& Bose, H. R., Jr. (2012). Insights into the evolution of mammalian telomerase: platypus TERT shares similarities with genes of birds and other reptiles and localizes on sex chromosomes. BMC Genomics, 13 , 216-216. doi:10.1186/1471-2164-13-216

Hurvich, C. M., \& Tsai, C.-L. (1989). Regression and time series model selection in small samples. Biometrika, 76 (2), 297-307. doi:10.1093/biomet/76.2.297

Jennings, B. J., Ozanne, S. E., Dorling, M. W., \& Hales, C. N. (1999). Early growth determines longevity in male rats and may be related to telomere shortening in the kidney. Febs Letters, 448 (1), 4-8. doi:10.1016/s0014-5793(99)00336-1 
Jensen, H., Sæther, B.-E., Ringsby, T. H., Tufto, J., Griffith, S. C., \& Ellegren, H. (2004). Lifetime reproductive success in relation to morphology in the house sparrow Passer domesticus. Journal of Animal Ecology, 73 (4), 599-611. doi:10.1111/j.0021-8790.2004.00837.x

Jensen, H., Steinsland, I., Ringsby, T. H., \& Saether, B. E. (2008). Evolutionary dynamics of a sexual ornament in the house sparrow (Passer domesticus): the role of indirect selection within and between sexes.Evolution, 62 (6), 1275-1293. doi:10.1111/j.1558-5646.2008.00395.x

Kingsolver, J. G., \& Pfennig, D. W. (2004). Individual-level selection as a cause of Cope's rule of phyletic size increase. Evolution, 58 (7), 1608-1612. doi:10.1111/j.0014-3820.2004.tb01740.x

Klapper, W., Heidorn, K., Kühne, K., Parwaresch, R., \& Guido, K. (1998). Telomerase activity in 'immortal' fish. Febs Letters, 434 (3), 409-412. doi:10.1016/s0014-5793(98)01020-5

Klimkiewicz, M. K., \& Futcher, A. G. (1987). Longevity records of North American birds: Coerebinae through Estrildidae. Journal of Field Ornithology, 58 (3), 318-333. Retrieved from

//WOS:A1987J520600011

Kvalnes, T., Ringsby, T. H., Jensen, H., Hagen, I. J., Rønning, B., Parn, H., . . . Sæther, B. E. (2017). Reversal of response to artificial selection on body size in a wild passerine. Evolution, 71 (8), 2062-2079. doi:10.1111/evo.13277

Lande, R. (1979). Quantitative genetic analysis of multivariate evolution, applied to brain:body size allometry. Evolution, 33 (1Part2), 402-416. doi:10.1111/j.1558-5646.1979.tb04694.x

Lansdorp, P. M. (1995). Telomere length and proliferation potential of hematopoietic stem cells. J Cell Sci, 108 ( Pt 1) (1), 1-6. Retrieved from https://www.ncbi.nlm.nih.gov/pubmed/7738087

Le Vaillant, M., Viblanc, V. A., Saraux, C., Le Bohec, C., Le Maho, Y., Kato, A., . . Ropert-Coudert, Y. (2015). Telomere length reflects individual quality in free-living adult king penguins. Polar Biology, 38 (12), 2059-2067. doi:10.1007/s00300-015-1766-0

Liker, A., \& Szekely, T. (2005). Mortality costs of sexual selection and parental care in natural populations of birds. Evolution, 59 (4), 890-897. doi:10.1111/j.0014-3820.2005.tb01762.x

McLennan, D., Armstrong, J. D., Stewart, D. C., McKelvey, S., Boner, W., Monaghan, P., . . Williams, T. (2017). Shorter juvenile telomere length is associated with higher survival to spawning in migratory Atlantic salmon. Functional Ecology, 31 (11), 2070-2079. doi:10.1111/1365-2435.12939

Metcalfe, N. B., \& Monaghan, P. (2003). Growth versus lifespan: perspectives from evolutionary ecology. Exp Gerontol, 38 (9), 935-940. doi:10.1016/s0531-5565(03)00159-1

Mizutani, Y., Tomita, N., Niizuma, Y., \& Yoda, K. (2013). Environmental perturbations influence telomere dynamics in long-lived birds in their natural habitat. Biol Lett, 9 (5), 20130511. doi:10.1098/rsbl.2013.0511

Monaghan, P. (2010). Telomeres and life histories: the long and the short of it. Ann N Y Acad Sci, 1206 , 130-142. doi:10.1111/j.1749-6632.2010.05705.x

Monaghan, P. (2014). Organismal stress, telomeres and life histories.J Exp Biol, 217 (Pt 1), 57-66. doi:10.1242/jeb.090043

Monaghan, P., \& Haussmann, M. F. (2006). Do telomere dynamics link lifestyle and lifespan? Trends Ecol Evol, 21 (1), 47-53. doi:10.1016/j.tree.2005.11.007

Monaghan, P., Metcalfe, N. B., \& Torres, R. (2009). Oxidative stress as a mediator of life history trade-offs: mechanisms, measurements and interpretation. Ecol Lett, 12 (1), 75-92. doi:10.1111/j.14610248.2008.01258.x 
Monaghan, P., \& Ozanne, S. E. (2018). Somatic growth and telomere dynamics in vertebrates: relationships, mechanisms and consequences.Philos Trans R Soc Lond B Biol Sci, 373 (1741), 20160446. doi:10.1098/rstb.2016.0446

Møller, A. P., Erritzoe, J., \& Soler, J. J. (2017). Life history, immunity, Peto's paradox and tumours in birds. J Evol Biol, 30 (5), 960-967. doi:10.1111/jeb.13060

National Oceanic and Atmospheric Administration (NOAA). (2018). Climate prediction center: North Atlantic Oscillation (NAO). Retrieved [01.12.2018] from https://www.cpc.ncep.noaa.gov/data/teledoc/nao.shtml.

Nettle, D., Andrews, C., Reichert, S., Bedford, T., Gott, A., Parker, C., . . . Bateson, M. (2016). Brood size moderates associations between relative size, telomere length, and immune development in European starling nestlings. Ecology and Evolution, 6 (22), 8138-8148. doi:10.1002/ece3.2551

Nettle, D., Andrews, C., Reichert, S., Bedford, T., Kolenda, C., Parker, C., . . Bateson, M. (2017). Earlylife adversity accelerates cellular ageing and affects adult inflammation: Experimental evidence from the European starling. Sci Rep, 7 , 40794. doi:10.1038/srep40794

Olsson, M., Pauliny, A., Wapstra, E., Uller, T., Schwartz, T., \& Blomqvist, D. (2011). Sex differences in sand lizard telomere inheritance: paternal epigenetic effects increases telomere heritability and offspring survival. PLoS One, 6 (4), e17473. doi:10.1371/journal.pone.0017473

Pauliny, A., Devlin, R. H., Johnsson, J. I., \& Blomqvist, D. (2015). Rapid growth accelerates telomere attrition in a transgenic fish.BMC Evol Biol, 15 (1), 159. doi:10.1186/s12862-015-0436-8

Pauliny, A., Wagner, R. H., Augustin, J., Szep, T., \& Blomqvist, D. (2006). Age-independent telomere length predicts fitness in two bird species. Mol Ecol, 15 (6), 1681-1687. doi:10.1111/j.1365-294X.2006.02862.x

Pepke, M. L., \& Eisenberg, D. T. A. (2020). On the comparative biology of mammalian telomeres: Telomere length co-evolves with body mass, lifespan and cancer risk. Authorea . doi:10.22541/au.159682209.91318403

Pepper, G. V., Bateson, M., \& Nettle, D. (2018). Telomeres as integrative markers of exposure to stress and adversity: a systematic review and meta-analysis. $R$ Soc Open Sci, 5 (8), 180744. doi:10.1098/rsos.180744

Peters, R. H. (1983). The ecological implications of body size . Cambridge Cambridgeshire ; New York: Cambridge University Press.

Pfaffl, M. W. (2001). A new mathematical model for relative quantification in real-time RT-PCR. Nucleic Acids Research, 29 (9), e45. doi:10.1093/nar/29.9.e45

Pick, J. L., Hatakeyama, M., Ihle, K. E., Gasparini, J., Haussy, C., Ishishita, S., . . Tschirren, B. (2020). Artificial selection reveals the role of transcriptional constraints in the maintenance of life history variation. Evol Lett, 4 (3), 200-211. doi:10.1002/evl3.166

Postma, E., Visser, J., \& Van Noordwijk, A. J. (2007). Strong artificial selection in the wild results in predicted small evolutionary change. J Evol Biol, 20 (5), 1823-1832. doi:10.1111/j.1420-9101.2007.01379.x

Pujol, B., Blanchet, S., Charmantier, A., Danchin, E., Facon, B., Marrot, P., . . . Winney, I. (2018). The missing response to selection in the wild. Trends Ecol Evol, 33 (5), 337-346. doi:10.1016/j.tree.2018.02.007

Pärn, H., Jensen, H., Ringsby, T. H., \& Sæther, B.-E. (2009). Sex-specific fitness correlates of dispersal in a house sparrow metapopulation. Journal of Animal Ecology, 78 (6), 1216-1225. doi:https://doi.org/10.1111/j.1365-2656.2009.01597.x

R Core Team. (2020). R: A language and environment for statistical computing. (Version 3.6.3). Vienna, Austria.: R Foundation for Statistical Computing. Retrieved from https://www.R-project.org/

Ranke, P. S., Skjelseth, S., Hagen, I. J., Billing, A. M., Pedersen, Å. A. B., Pärn, H., . . Jensen, H. (2020). Multi-generational genetic consequences of reinforcement in a bird metapopulation. Conservation Genetics, 21 (3), 603-612. doi:10.1007/s10592-020-01273-7 
Reichert, S., \& Stier, A. (2017). Does oxidative stress shorten telomeres in vivo? A review. Biology Letters, 13(12), 20170463. doi:10.1098/rsbl.2017.0463

Reznick, D. (1985). Costs of reproduction: An evaluation of the empirical evidence. Oikos, 44 (2), 257-267. doi: $10.2307 / 3544698$

Ringsby, T. H., Jensen, H., Pärn, H., Kvalnes, T., Boner, W., Gillespie, R., . . Monaghan, P. (2015). On being the right size: increased body size is associated with reduced telomere length under natural conditions. Proc Biol Sci, 282 (1820), 20152331. doi:10.1098/rspb.2015.2331

Ringsby, T. H., Sæther, B.-E., \& Solberg, E. J. (1998). Factors affecting juvenile survival in house sparrow Passer domesticus .Journal of Avian Biology, 29 (3), 241-247. doi:10.2307/3677106

Ringsby, T. H., Sæther, B.-E., Tufto, J., Jensen, H., \& Solberg, E. J. (2002). Asynchronous spatiotemporal demography of a house sparrow metapopulation in a correlated environment. Ecology, 83 (2), 561-569. doi:10.1890/0012-9658(2002)083[0561:Asdoah]2.0.Co;2

Rising, J. D., \& Somers, K. M. (1989). The measurement of overall body size in birds. The Auk, 106 (4), 666-674. Retrieved from //WOS:A1989AY24300016

Roff, D. A., \& Fairbairn, D. J. (2007). The evolution of trade-offs: where are we? Journal of Evolutionary Biology, 20 (2), 433-447. doi:https://doi.org/10.1111/j.1420-9101.2006.01255.x

Rønning, B., Broggi, J., Bech, C., Moe, B., Ringsby, T. H., Pärn, H., . . Jensen, H. (2016). Is basal metabolic rate associated with recruit production and survival in free-living house sparrows? Functional Ecology, 30 (7), 1140-1148. doi:10.1111/1365-2435.12597

Schulte-Hostedde, A. I., Zinner, B., Millar, J. S., \& Hickling, G. J. (2005). Restitution of mass-size residuals: Validating body condition indices. Ecology, 86 (1), 155-163. doi:10.1890/04-0232

Scott, N. M., Haussmann, M. F., Elsey, R. M., Trosclair, P. L., \& Vleck, C. M. (2006). Telomere length shortens with body length inAlligator mississippiensis . Southeastern Naturalist, 5 (4), 685-692. doi:10.1656/1528-7092(2006)5[685:Tlswbl]2.0.Co;2

Selman, C., Blount, J. D., Nussey, D. H., \& Speakman, J. R. (2012). Oxidative damage, ageing, and life-history evolution: where now? Trends Ecol Evol, 27 (10), 570-577. doi:10.1016/j.tree.2012.06.006

Seluanov, A., Gladyshev, V. N., Vijg, J., \& Gorbunova, V. (2018). Mechanisms of cancer resistance in long-lived mammals. Nat Rev Cancer, 18 (7), 433-441. doi:10.1038/s41568-018-0004-9

Sibly, R. M., \& Brown, J. H. (2007). Effects of body size and lifestyle on evolution of mammal life histories. Proceedings of the National Academy of Sciences, 104 (45), 17707. doi:10.1073/pnas.0707725104

Sidorov, I., Kimura, M., Yashin, A., \& Aviv, A. (2009). Leukocyte telomere dynamics and human hematopoietic stem cell kinetics during somatic growth. Exp Hematol, 37 (4), 514-524. doi:10.1016/j.exphem.2008.11.009

Simons, M. J. (2015). Questioning causal involvement of telomeres in aging. Ageing Res Rev, 24 (Pt B), 191-196. doi:10.1016/j.arr.2015.08.002

Smith, S. M., Nager, R. G., \& Costantini, D. (2016). Meta-analysis indicates that oxidative stress is both a constraint on and a cost of growth. Ecology and Evolution, 6 (9), 2833-2842. doi:10.1002/ece3.2080

Spurgin, L. G., Bebbington, K., Fairfield, E. A., Hammers, M., Komdeur, J., Burke, T., . . . Richardson, D. S. (2018). Spatio-temporal variation in lifelong telomere dynamics in a long-term ecological study. J Anim Ecol, 87 (1), 187-198. doi:10.1111/1365-2656.12741

Stearns, S. C. (1989). Trade-offs in life-history evolution.Functional Ecology, 3 (3), 259-268. doi:10.2307/2389364 
Steinsland, I., Larsen, C. T., Roulin, A., \& Jensen, H. (2014). Quantitative genetic modeling and inference in the presence of nonignorable missing data. Evolution, 68 (6), 1735-1747. doi:10.1111/evo.12380

Stenseth, N. C., Ottersen, G., Hurrell, J. W., Mysterud, A., Lima, M., Chan, K. S., . . . Adlandsvik, B. (2003). Review article. Studying climate effects on ecology through the use of climate indices: the North Atlantic Oscillation, El Nino Southern Oscillation and beyond.Proc Biol Sci, 270 (1529), 2087-2096. doi:10.1098/rspb.2003.2415

Sudyka, J. (2019). Does reproduction shorten telomeres? Towards integrating individual quality with lifehistory strategies in telomere biology. Bioessays, 41 (11), e1900095. doi:10.1002/bies.201900095

Sudyka, J., Podmokla, E., Drobniak, S. M., Dubiec, A., Arct, A., Gustafsson, L., \& Cichon, M. (2019). Sex-specific effects of parasites on telomere dynamics in a short-lived passerine-the blue tit. Die Naturwissenschaften, 106 (1-2), 6. doi:10.1007/s00114-019-1601-5

The Norwegian Meteorological Institute. (2018). eKlima. Retrieved from http://eklima.met.no. Retrieved 01.12.2018 http://eklima.met.no

Therneau, T. (2015). A package for survival analysis in S. doi:https://CRAN.Rproject.org $/$ package $=$ survival

Trivers, R. (1985). Social evolution: Benjamin/Cummings Pub. Co.

Ujvari, B., \& Madsen, T. (2009). Short telomeres in hatchling snakes: erythrocyte telomere dynamics and longevity in tropical pythons.PLoS One, 4 (10), e7493. doi:10.1371/journal.pone.0007493

van de Crommenacker, J., Komdeur, J., Burke, T., \& Richardson, D. S. (2011). Spatio-temporal variation in territory quality and oxidative status: a natural experiment in the Seychelles warbler (Acrocephalus sechellensis). J Anim Ecol, 80 (3), 668-680. doi:10.1111/j.1365-2656.2010.01792.x

van Noordwijk, A. J., \& de Jong, G. (1986). Acquisition and allocation of resources: Their influence on variation in life history tactics. The American Naturalist, 128 (1), 137-142. doi:10.1086/284547

Vaziri, H., Dragowska, W., Allsopp, R. C., Thomas, T. E., Harley, C. B., \& Lansdorp, P. M. (1994). Evidence for a mitotic clock in human hematopoietic stem cells: loss of telomeric DNA with age. Proc Natl Acad Sci U S A, 91 (21), 9857-9860. doi:10.1073/pnas.91.21.9857

Vedder, O., Verhulst, S., Bauch, C., \& Bouwhuis, S. (2017). Telomere attrition and growth: a life-history framework and case study in common terns. J Evol Biol, 30 (7), 1409-1419. doi:10.1111/jeb.13119

Vedder, O., Verhulst, S., Zuidersma, E., \& Bouwhuis, S. (2018). Embryonic growth rate affects telomere attrition: an experiment in a wild bird. J Exp Biol, 221 (Pt 15), jeb181586. doi:10.1242/jeb.181586

Verhulst, S., Aviv, A., Benetos, A., Berenson, G. S., \& Kark, J. D. (2013). Do leukocyte telomere length dynamics depend on baseline telomere length? An analysis that corrects for 'regression to the mean'.Eur $J$ Epidemiol, 28 (11), 859-866. doi:10.1007/s10654-013-9845-4

von Zglinicki, T. (2002). Oxidative stress shortens telomeres. Trends Biochem Sci, 27 (7), 339-344. doi:10.1016/s0968-0004(02)02110-2

Wang, Q., Zhan, Y., Pedersen, N. L., Fang, F., \& Hagg, S. (2018). Telomere Length and All-Cause Mortality: A Meta-analysis. Ageing Res Rev, 48 , 11-20. doi:10.1016/j.arr.2018.09.002

Watson, H., Bolton, M., \& Monaghan, P. (2015). Variation in early-life telomere dynamics in a long-lived bird: links to environmental conditions and survival. J Exp Biol, 218 (Pt 5), 668-674. doi:10.1242/jeb.104265

White, C. R., Marshall, D. J., Alton, L. A., Arnold, P. A., Beaman, J. E., Bywater, C. L., . . . OrtizBarrientos, D. (2019). The origin and maintenance of metabolic allometry in animals. Nat Ecol Evol, 3 (4), 598-603. doi:10.1038/s41559-019-0839-9 
Wilbourn, R. V., Froy, H., McManus, M. C., Cheynel, L., Gaillard, J. M., Gilot-Fromont, E., . . . Nussey, D. H. (2017). Age-dependent associations between telomere length and environmental conditions in roe deer. Biol Lett, 13 (9), 20170434. doi:10.1098/rsbl.2017.0434

Wilbourn, R. V., Moatt, J. P., Froy, H., Walling, C. A., Nussey, D. H., \& Boonekamp, J. J. (2018). The relationship between telomere length and mortality risk in non-model vertebrate systems: a meta-analysis.Philos Trans R Soc Lond B Biol Sci, 373 (1741), 20160447. doi:10.1098/rstb.2016.0447

Wilson, A. J., \& Nussey, D. H. (2010). What is individual quality? An evolutionary perspective. Trends Ecol Evol, 25 (4), 207-214. doi:10.1016/j.tree.2009.10.002

Wood, E. M., \& Young, A. J. (2019). Telomere attrition predicts reduced survival in a wild social bird, but short telomeres do not. Mol Ecol, 28 (16), 3669-3680. doi:10.1111/mec.15181

Woodward, G., Ebenman, B., Emmerson, M., Montoya, J. M., Olesen, J. M., Valido, A., \& Warren, P. H. (2005). Body size in ecological networks. Trends Ecol Evol, 20 (7), 402-409. doi:10.1016/j.tree.2005.04.005

Young, A. J. (2018). The role of telomeres in the mechanisms and evolution of life-history trade-offs and ageing. Philos Trans R Soc Lond B Biol Sci, 373 (1741), 20160452. doi:10.1098/rstb.2016.0452

Zera, A. J., \& Harshman, L. G. (2001). The physiology of life history trade-offs in animals. Annual Review of Ecology and Systematics, 32 (1), 95-126. doi:10.1146/annurev.ecolsys.32.081501.114006

\section{DATA ACCESSIBILITY}

All data will be made available on the Dryad Digital Repository or another open access channel upon acceptance of the manuscript.

\section{AUTHOR CONTRIBUTIONS}

MLP analyzed the data and wrote the manuscript with input from all authors. MLP and WB measured telomere lengths. MLP and BR constructed pedigrees. THR, HJ and B-ES designed the artificial selection experiment. THR, HJ \& BR contributed to the fieldwork and TK curated field data.

\section{FIGURES AND TABLES}

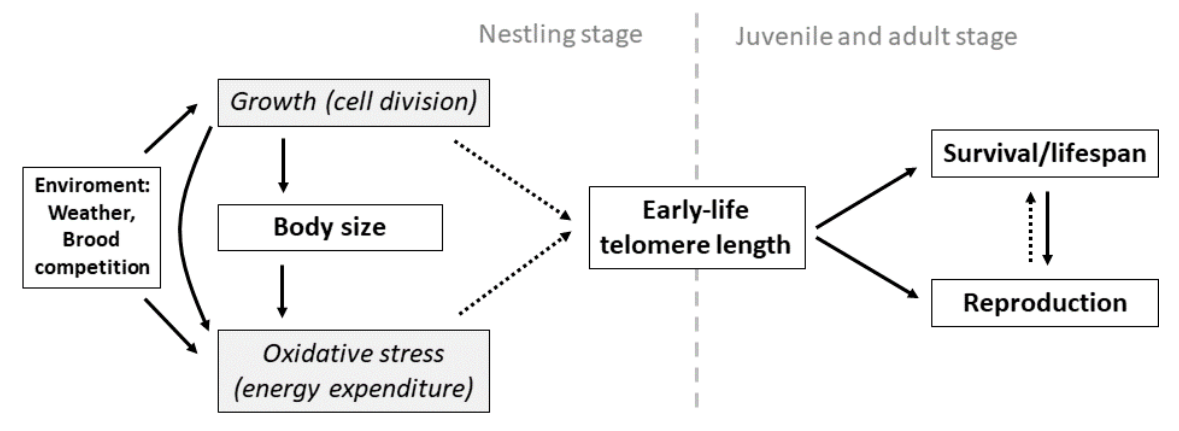

Fig. 1: Hypotheses of expected positive (solid lines) and negative (dotted lines) effects shaping variation in early-life telomere length during the nestling stage, and later-life fitness consequences. 


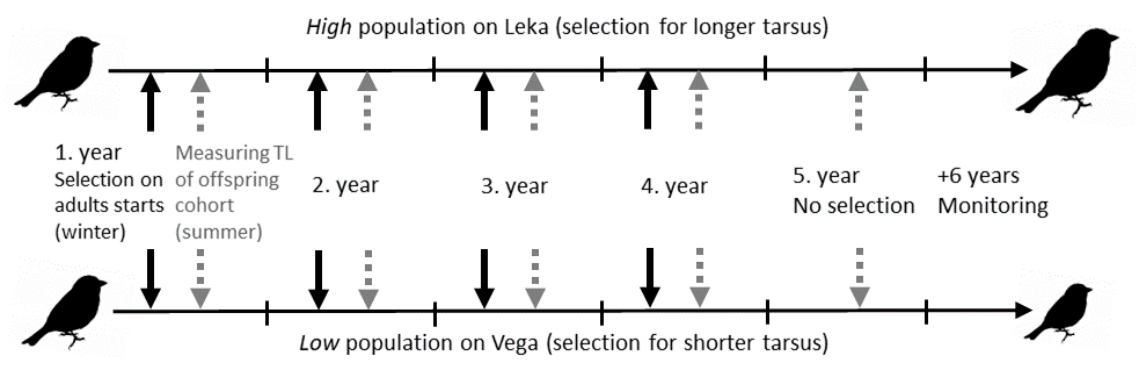

Fig. 2: Timeline of the artificial size selection experiment on free-living house sparrows conducted in parallel on two islands in Norway starting in year $2002\left(1^{\text {st }}\right.$ year$)$. Adult birds were captured each winter for 4 years and selected for either longer or shorter tarsus length (each selection event showed with a solid black arrow). Telomere lengths (TL) were measured on nestling cohorts produced in the subsequent summer breeding season (showed as dotted grey arrows). Birds that were not removed during the artificially selection stayed in their populations, and survival and recruit production were monitored until all sampled birds were assumed to had died.

Table 1: Number of sampled offspring $(n=566)$ in each artificial selection category (1: both parents artificially selected; 0.5 : one parent subject to artificial selection; 0: no parents artificially selected, i.e. unselected) from year 2002-2006 in two island populations selected for larger (high ) and smaller (low ) tarsus length, respectively. Unknown genetic parents were assumed not to have been artificially selected.

\begin{tabular}{llllllll}
\hline Population: & High (Leka) & High (Leka) & High (Leka) & High (Leka) & High (Leka) & High (Leka) & Low (Vega) \\
\hline Selection category: & $\mathbf{2 0 0 2}$ & $\mathbf{2 0 0 3}$ & $\mathbf{2 0 0 4}$ & $\mathbf{2 0 0 5}$ & $\mathbf{2 0 0 6}$ & Sum: & $\mathbf{2 0 0 2}$ \\
Selected (1) & 5 & 18 & 16 & 21 & 14 & $\mathbf{7 5}$ & 45 \\
Intermediate (0.5) & 26 & 5 & 3 & 12 & 13 & $\mathbf{5 9}$ & 54 \\
Unselected (0) & 16 & 3 & 3 & 2 & 1 & $\mathbf{2 5}$ & 21 \\
Sum: & $\mathbf{4 7}$ & $\mathbf{2 6}$ & $\mathbf{2 2}$ & $\mathbf{3 5}$ & $\mathbf{2 8}$ & $\mathbf{1 5 8}$ & $\mathbf{1 2 0}$ \\
\hline
\end{tabular}

a)
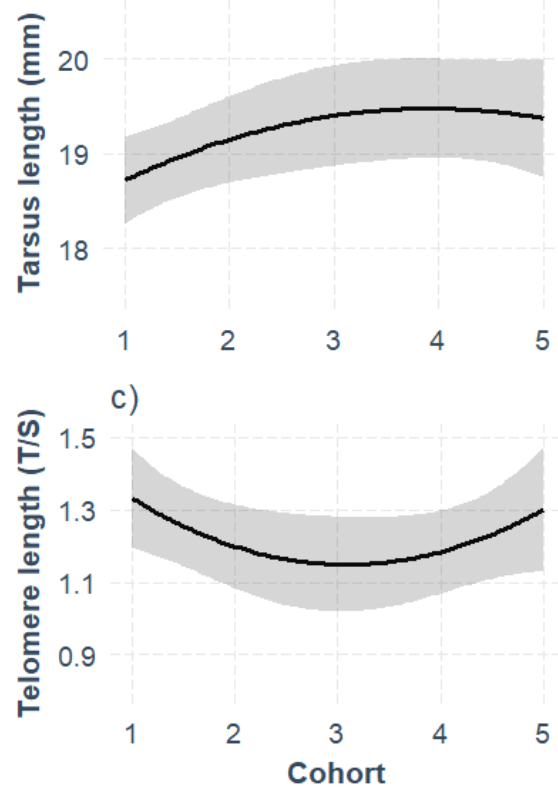

b)

20

19

18

d)

1.5

1.3

1.1

0.9

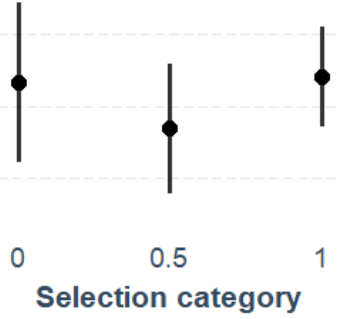


Fig. 3: High population; effect plots of trends in nestling tarsus (a) and telomere lengths (c) during artificial selection for larger tarsus length in parents. The artificial selection ended after cohort 4 was born. The effect of selection category ( 0 : no parents selected (unselected), $0.5:$ one parent selected, and 1 : both parents selected) on tarsus (b) and telomere length (d) is shown.

a)

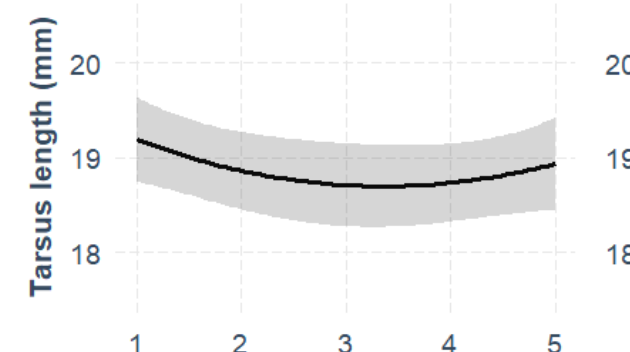

c)

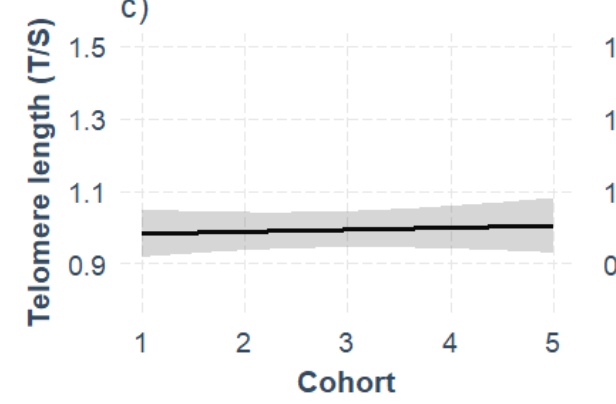

b)

20

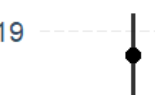

8

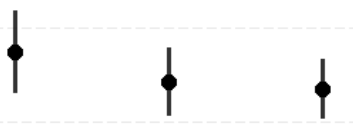

$\begin{array}{lll}0 & 0.5 & 1\end{array}$

d)

1.5

1.3

1.1

0.9

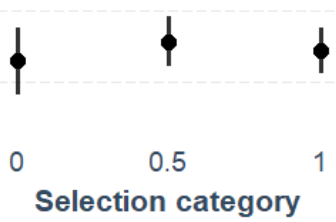

Fig. 4: Low population; effect plots of trends in nestling tarsus (a) and telomere lengths (c) during artificial selection for smaller tarsus length in parents. The artificial selection ended after cohort 4 was born. The effect of selection category ( 0 : no parents selected (unselected), $0.5:$ one parent selected, and 1 : both parents selected) on tarsus (b) and telomere length (d) is shown.

Table 2: Linear mixed effects models with [?]AICc $<5$ of variation in early-life telomere length in house sparrow nestlings $(n=566)$ in two island populations. All models included random intercepts for brood identity and year. The models are ranked by AICc, and number of degrees of freedom (df) and model weights (w) are shown.

\begin{tabular}{|c|c|c|c|c|}
\hline Model & Model & [?]AICc & df & $\mathrm{w}$ \\
\hline 1 & $T L=$ sex + population + tarsus $+N A O \_30$ & 0.0 & 8 & 0.203 \\
\hline 2 & $T L=$ sex + population + tarsus + NAO_30 + population ${ }^{*}$ tarsus & 0.2 & 9 & 0.180 \\
\hline 3 & $T L=$ sex + population + age + tarsus + NAO_30 & 1.4 & 9 & 0.099 \\
\hline 4 & $T L=$ sex + population + age + tarsus $+N A O \_30+$ population ${ }^{*}$ tarsus & 1.7 & 10 & 0.088 \\
\hline 5 & $T L=$ sex + population + tarsus + NAO_30 + brood size & 2.1 & 9 & 0.072 \\
\hline 6 & $T L=$ sex + population + tarsus + NAO_ $30+$ population ${ }^{*}$ tarsus + brood size & 2.3 & 10 & 0.064 \\
\hline 7 & $T L=$ sex + population + NAO_30 & 2.3 & 7 & 0.064 \\
\hline 8 & $T L=$ sex + population + tarsus & 2.9 & 7 & 0.048 \\
\hline 9 & $T L=$ sex + population + tarsus + population ${ }^{*}$ tarsus & 3.2 & 8 & 0.041 \\
\hline 10 & $T L=$ sex + population + age + tarsus + NAO_30 + brood size & 3.5 & 10 & 0.035 \\
\hline 11 & $T L=$ sex + population + age + tarsus $+N A O \_30+$ brood size + population ${ }^{*}$ tarsus & 3.7 & 11 & 0.031 \\
\hline 12 & $T L=$ sex + population + age + NAO_30 & 3.8 & 8 & 0.031 \\
\hline 13 & $T L=$ sex + population + age + tarsus & 4.3 & 8 & 0.024 \\
\hline
\end{tabular}




\begin{tabular}{lllll}
\hline Model & Model & {$[?]$ AICc } & df & w \\
\hline 14 & $T L=$ sex + population + age + tarsus + population ${ }^{*}$ tarsus & 4.7 & 9 & 0.020 \\
\hline
\end{tabular}

Table 3: Estimates $(\beta)$ with standard errors (SE) and lower and upper $95 \%$ confidence intervals (CI) from a linear mixed effects model of variation in telomere length (TL, $n=566)$. Random intercepts for brood identity and year were included in the model.

\begin{tabular}{|c|c|c|}
\hline Response variable: TL & $\beta$ & $\mathrm{SE}$ \\
\hline intercept & 1.19 & 0.04 \\
\hline tarsus & -0.03 & 0.01 \\
\hline sex (female) & -0.08 & 0.03 \\
\hline population (low) & -0.17 & 0.04 \\
\hline NAO_30 & 0.10 & 0.05 \\
\hline$\sigma^{2} \beta \rho \circ o \delta I \Delta$ & $0.00 \pm 0.05 \mathrm{SD}$ & $0.00 \pm 0.05 \mathrm{SD}$ \\
\hline$\sigma_{\psi \epsilon a \rho}^{2}$ & $0.00 \pm 0.02 \mathrm{SD}$ & $0.00 \pm 0.02 \mathrm{SD}$ \\
\hline Marginal $R^{2} /$ Conditional $R^{2}: 0.070 / 0.092$ & Marginal $\mathrm{R}^{2}$ / Conditional $\mathrm{R}^{2}: 0.070$ / 0.092 & Marginal $\mathrm{R}^{2}$ / Conditional \\
\hline
\end{tabular}

a)

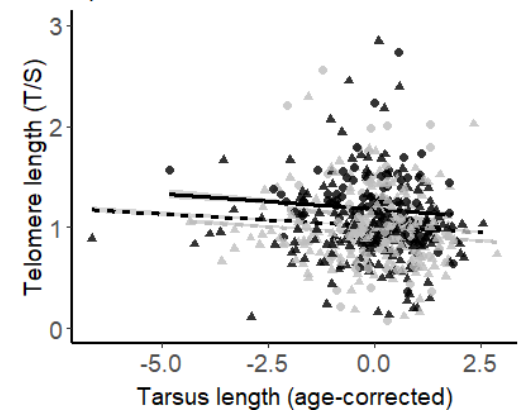

b)

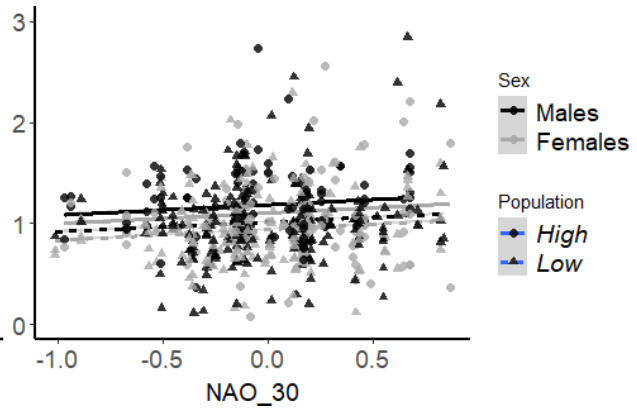

Fig. 5: The relationship between nestling telomere length (TL) and (a) age-corrected tarsus length and (b) the NAO_30 index (the average NAO index across 30 days prior to TL measurement) with regression lines based on the highest ranked model according to the AICc (Tables 2 and 3). Although there is considerable variation in TLs among individuals of similar size, tarsus length and the NAO_30 index significantly correlate with TL. Males (black) have longer telomeres than females (grey) and individuals in thehigh population (circles, full line) have longer telomeres than those in the low population (triangles, dotted line).

Table 4: Binomial generalized linear mixed models with [?]AICc $<5$ of variation in first-year survival in house sparrows in two island populations. All models included random intercepts for brood identity and year. The models are ranked by AICc, and number of degrees of freedom (df) and model weights (w) are shown.

\begin{tabular}{|c|c|c|c|c|}
\hline & Model & [?]AICc & df & $\mathrm{w}$ \\
\hline 1 & Survival $=$ sex + population + tarsus + tarsus $^{2}$ & 0.0 & 7 & 0.179 \\
\hline 2 & Survival $=$ sex + population + tarsus & 1.2 & 6 & 0.010 \\
\hline 3 & Survival $=$ sex + population + tarsus + population $*$ tarsus & 1.5 & 7 & 0.083 \\
\hline 4 & Survival $=$ sex + population & 1.7 & 5 & 0.075 \\
\hline 5 & Survival $=$ sex + population + tarsus + tarsus $^{2}+T L$ & 1.9 & 8 & 0.070 \\
\hline 6 & Survival $=$ sex + population + tarsus + tarsus $^{2}+N A O \_30$ & 2.0 & 8 & 0.065 \\
\hline
\end{tabular}




\begin{tabular}{lllll}
\hline & Model & {$[?] \mathrm{AICc}$} & $\mathrm{df}$ & $\mathrm{w}$ \\
\hline 7 & Survival $=$ sex + population + tarsus + tarsus $^{2}+T L+T L^{2}$ & 2.5 & 9 & 0.052 \\
8 & Survival $=$ sex + population + tarsus $+T L$ & 3.0 & 7 & 0.040 \\
9 & Survival $=$ sex + population + tarsus $+N A O \_30$ & 3.2 & 7 & 0.036 \\
10 & Survival $=$ sex + population + tarsus + population ${ }^{*}$ tarsus $+T L$ & 3.4 & 8 & 0.032 \\
11 & Survival $=$ sex + population $+T L$ & 3.5 & 6 & 0.032 \\
12 & Survival $=$ sex + population + tarsus + population ${ }^{*}$ tarsus $+N A O \_30$ & 3.6 & 8 & 0.030 \\
13 & Survival $=$ sex + population $+N A O \_30$ & 3.7 & 6 & 0.028 \\
14 & Survival $=$ sex + population + tarsus $+T L+T L^{2}$ & 3.7 & 8 & 0.028 \\
15 & Survival $=$ sex + population + tarsus + tarsus $^{2}+T L+N A O_{-30} 30$ & 3.9 & 9 & 0.025 \\
16 & Survival $=$ sex + population $+T L+T L^{2}$ & 4.2 & 7 & 0.022 \\
17 & Survival $=$ sex + population + tarsus + tarsus $^{2}+T L+T L^{2}+N A O \_30$ & 4.5 & 10 & 0.019 \\
\hline
\end{tabular}

a)

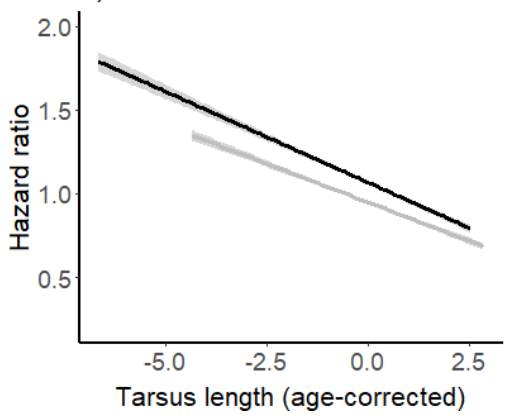

b)

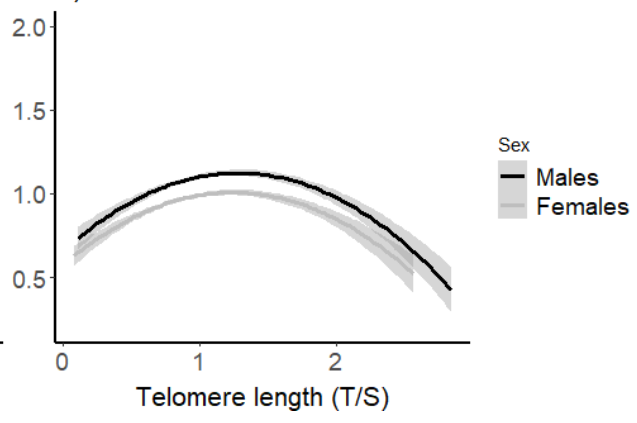

Fig. 6: Cox proportional hazards regression models showing predicted values of hazard ratios (i.e. mortality risk) with $95 \%$ confidence intervals as a function of a) tarsus length, and b) telomere length for each sex. Differences between sexes were not significant. Larger individuals had lower long-term mortality, and model selection indicated a tendency for both short and long telomeres to be associated with lower mortality.

Table 5: Estimates with 95\% confidence intervals (CI) and standard errors (SE) from the highest ranked generalized linear models (see Table S2.5) fitted using a Poisson distribution of variation in lifetime reproductive success (LRS) corrected for lifespan for each population (high / low ). Random intercepts for brood identity and year were included as random factors in all models. Only individuals that were not removed during the artificial selection and that survived until breeding were included in these analyses.

\begin{tabular}{|c|c|c|c|c|}
\hline High $(n=22)$ : LRS & $\beta$ & $\mathrm{SE}$ & Lower CI & Upper CI \\
\hline intercept & 0.03 & 0.72 & -1.39 & 1.45 \\
\hline lifespan & 0.72 & 0.15 & 0.43 & 1.00 \\
\hline sex (female) & -1.11 & 0.58 & -2.25 & 0.03 \\
\hline TL & -1.24 & 0.65 & -2.52 & 0.04 \\
\hline 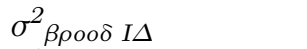 & $0.00 \pm 0.00$ & $0.00 \pm 0.00$ & 0.00 & 0.00 \\
\hline $\begin{array}{l}\sigma_{\psi \in \alpha \rho}^{2} \\
\text { Low }(n=80): \text { LRS }\end{array}$ & $0.00 \pm 0.00$ & $0.00 \pm 0.00$ & 0.00 & 0.00 \\
\hline intercept & -2.01 & 0.43 & -2.86 & -1.16 \\
\hline lifespan & 0.93 & 0.14 & 0.66 & 1.20 \\
\hline sex (female) & -0.03 & 0.35 & -0.71 & 0.65 \\
\hline$\sigma^{2} \beta \rho \circ о \delta$ I $\Delta$ & $0.56 \pm 0.75$ & $0.56 \pm 0.75$ & 0.45 & 1.26 \\
\hline$\sigma_{\psi \in a \rho}^{2}$ & $0.05 \pm 0.23$ & $0.05 \pm 0.23$ & 0.01 & 4.12 \\
\hline
\end{tabular}




\section{SUPPORTING INFORMATION}

Additional Supporting Information may be found in the online version of this article.

Appendix S1: Notes on methods.

Appendix S2: Notes on results. 